IZA DP No. 7571

A Provocative Perspective on Population Aging and Old-Age Financial Protection

Robert Holzmann

August 2013 


\title{
A Provocative Perspective on Population Aging and Old-Age Financial Protection
}

\author{
Robert Holzmann \\ University of Malaya, \\ CEPAR, IZA and CESifo
}

\section{Discussion Paper No. 7571 \\ August 2013}

\author{
IZA \\ P.O. Box 7240 \\ 53072 Bonn \\ Germany \\ Phone: +49-228-3894-0 \\ Fax: +49-228-3894-180 \\ E-mail: iza@iza.org
}

Any opinions expressed here are those of the author(s) and not those of IZA. Research published in this series may include views on policy, but the institute itself takes no institutional policy positions. The IZA research network is committed to the IZA Guiding Principles of Research Integrity.

The Institute for the Study of Labor (IZA) in Bonn is a local and virtual international research center and a place of communication between science, politics and business. IZA is an independent nonprofit organization supported by Deutsche Post Foundation. The center is associated with the University of Bonn and offers a stimulating research environment through its international network, workshops and conferences, data service, project support, research visits and doctoral program. IZA engages in (i) original and internationally competitive research in all fields of labor economics, (ii) development of policy concepts, and (iii) dissemination of research results and concepts to the interested public.

IZA Discussion Papers often represent preliminary work and are circulated to encourage discussion. Citation of such a paper should account for its provisional character. A revised version may be available directly from the author. 


\section{ABSTRACT \\ A Provocative Perspective on Population Aging and Old-Age Financial Protection}

Population aging is typically associated with economic challenges for productivity and financial threats for the old-age financial protection system of a country. This paper takes an optimistic position and outlines key ingredients to make it a successful experience. Yet to turn this challenge into an opportunity requires a significant change in a society's mindset and policies, such as recognizing that population aging and increased life expectancy are quite likely the biggest challenge to mankind in recorded history. This calls for a review and revision of societal institutions, from the likely oldest one - marriage - to one of the youngest - retirement income schemes. Mere tinkering at the margin of existing retirement income programs will be neither sufficient nor helpful. To develop the arguments, the paper reviews and proposes changes to the measurement of population aging - globally and for East Asian countries; outlines critical policy paths to address population aging successfully; analyzes the implications of population aging for the selection of an old-age financial protection system; and offers guidance to this end.

JEL Classification: H55, J11, J14, J26

Keywords: life expectancy, measuring population aging, happy aging, NDC, FDC

Corresponding author:

Robert Holzmann

Chair of Old-Age Financial Protection

Faculty of Economics and Administration

University of Malaya

Kuala Lumpur

Malaysia

E-mail: Robert.Holzmann@um.edu.my

\footnotetext{
* The initial thoughts and versions of this paper were presented at various conferences across the world including the International Conference on Population Ageing: Issues and Challenges (University of Malaya, Kuala Lumpur, July 2012), International Seminar Series (University of New South Wales, Sydney 2011), and $4^{\text {th }}$ World Ageing \& Generations Congress (St. Gallen, August 2009). The paper has benefited for comments and critical suggestions by the participants, written comments by Agnieszka Chlon, John Piggott, and Vegard Skirbekk, superb research assistance by Tan Lih Yoong, and editing by Amy Gautam.

The views presented in this paper cannot be attributed to any institution with which the author is associated and any errors are his own doing.
} 


\section{Introduction: Motivation and Structure}

In all countries of the world, the population is aging by at least one measure. In most low- and middle-income countries (LICs and MICs), the projected population aging is very fast compared to that of the high-income countries (HICs), in which the level of population aging is already the most advanced. In rich countries, concerns about population aging and its impact on the financing of old-age financial security is by now an evergreen in the economic and social policy discourse. But while HICs became economically rich before getting demographically old, most LICs and many MICs risk getting demographically old before becoming economically rich. ${ }^{1}$ Thus aging in these less advanced countries seemingly creates an almost insurmountable challenge for old-age income support and other age-related public and private programs.

The rapid demographic change occurring inversely to countries' development level is drastically visible in Figure 1. The graph compares the age pyramid for the world as a whole in 2000 and 2050, as well as for three development levels of countries (using a UN definition that is broadly, but not fully, equivalent to the World Bank's income level characterization of HICs, MICs, and LICs). For the world as a whole, the demographic structure by age and sex in 2000 still broadly resembles a pyramid; by 2050, it resembles a honeycomb. Yet the starkest change happens in the least developed countries: in 2000, their demographic structure is a flat pyramid (as were those of HICs until the $20^{\text {th }}$ century); by 2050, their pyramid almost resembles the honeycomb of the more developed countries in 2000.

Figure 1: Population Pyramids: Age and Sex Distribution, 2000 and 2050

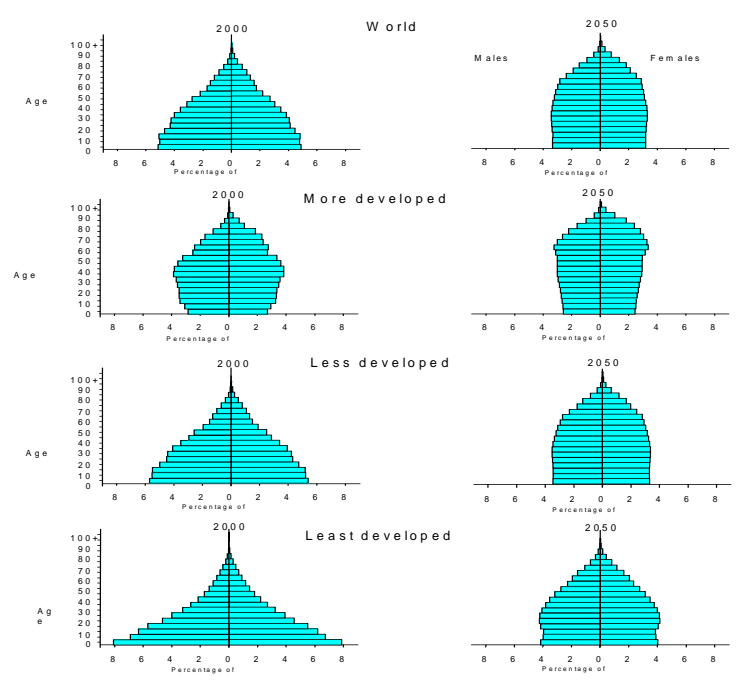

Source: UN 2002.

\footnotetext{
${ }^{1}$ The author prides himself on having coined this statement at the Second World Assembly on Ageing in Madrid, October 2002, in a presentation entitled "Old-Age Income Support for the $21^{\text {st }}$ Century." If he received 1 cent for each time this statement was used, his retirement prospective would look even brighter...
} 
The challenge of population aging for social cohesion, the economy, and the public budget is by now a well-internalized refrain in the more developed countries. Behind the angst of aging, one may conjecture two key concerns: At the individual level, old age is historically associated with being poor, sick, marginalized, and dependent, and in many countries, this is still the case, particularly the lower the income level. ${ }^{2}$ At the aggregate level, the angst of aging is largely prospective and reflects concerns about the impact of population aging on key drivers of welfare, such as innovation and economic growth, budget outlays and debt level, size of work forces, and levels of social services.

But is this pessimistic view of population aging justified? Does it not contradict individuals' aspirations and mankind's dream to live ever longer? And is the view of unavoidable development not in contrast to the successes of society against poverty, disease, and hopefully also human-influenced climate change?

This paper takes an optimistic view on individual aging (i.e., living longer) and population aging (simply put, having a larger share of elderly in the population) and asks: What does it require to age and retire happily? What are the ingredients for happy aging at the individual/ micro-economic level? What are the ingredients needed at the societal/macroeconomic level? And which old-age income schemes support this happy vision without creating a fiscal megathreat? The paper asserts that the ingredients for happy aging and retirement do indeed exist. However, to turn this challenge into an opportunity requires a significant change in a society's mindset and policies.

To develop the key arguments, the structure of the paper is as follows: Section 2 addresses a few simple but crucial questions: What do we mean by aging and how can we best measure it? Isn't it time to rethink and replace our traditional measurement of aging with more adequate concepts being proposed? Does aging necessarily reduce productivity? Section 3 asks about the critical policy paths to address population aging successfully: What is required for individuals to age happily? What is required for economies to handle the economic implications? What is required politically to focus the mind of society and decision makers? And last but not least, what are the key policy areas that need adjustments? Section 4 zooms in on the implications of population aging for the choice of a society's old-age financial protection system: How can consumption smoothing be reorganized across a lengthening life cycle? What are the candidate retirement schemes? What are the international trends in pension reform? Section 5 provides some final conclusions with an outlook to the future.

\section{Measuring Population Aging and its Economic Effects}

Having a joint understanding of what one is talking about is critical for any policy discourse or academic analysis. This section aims to offer such a joint understanding and addresses three issues: (i) the traditional view on population aging, with some clarifications, concerns, and trends for the region of the world and countries in East Asia; (ii) a revision of the view and

\footnotetext{
${ }^{2}$ The empirical studies on the link between age and subjective well-being typically suggest for Europe and the U.S. a U-shaped relationship, with its minimum between 30 and 50 years depending on data used (cross-section or panel), controlling variables, and estimation approach. For low- and middle-income countries, this curvature seems less prevalent and well-being typically falls with age. The latter is emerging also in high-income countries but only at the higher ages of 70/75. For a recent and excellent review of literature on this topic, see Lopez-Ulloa et al. 2013.
} 
measurement of population aging in the face of rising life expectancy and decreasing morbidity et al.; and (iii) a dynamic view of population aging and economic productivity.

\section{(i) The traditional view on population aging: clarifications, concerns, and trends}

For an individual, aging seems relatively easily defined as getting older by the day (or year), but what "being old" means is still a question of social appreciation or individual definition. The latter may include defining a person who is 20 years our senior as old. Thus if few are left in this (our) category, we are really old.

The definition of population aging is faced with two key choices: What measure to use and from what age onward to consider age cohorts as old. Regarding the measure of population aging, four main concepts are typically used, each with different information and implications for policy settings. All move in the same direction under steady state conditions, but differences emerge outside the steady state in an often long transition. The four concepts are:

(a) An increase in the number of old people. This measure is, inter alia, relevant for the provision of services and number of staff to be hired to provide age-related services. To this end, different age limits are chosen at times to signal different service demand: e.g., the elderly (or old) are those above 60 or 65 ; the very old are those above 80 or 85 ; and centenarians are those above 100 (and they are actually the fastest growing age group across the world, albeit often not yet well captured statistically).

(b) An increasing share of old people in the population (Old Age Share-OAS). This measure is, inter alia, relevant for signaling changes in society.

(c) An increase in the ratio of the elderly to active population (Old-Age Demographic Dependency Ratio - OADDR). This ratio is, inter alia, relevant to signal potential issues with the financing of social benefits and services. It proxies the number of potential beneficiaries to the number of potential contributors or (income) tax payers and the burden is directly measured through the ratio of actual beneficiaries to contributors, also called the Old-Age System Dependency Ratio - OASDR.

(d) An increase in the median age of the population. The median age concept is typically preferred over other means as it simply divides the population in half: those that are younger than the median age and those that are older. Median age measures (with and without those not yet voting) are often used in political economy analyses where median voter concepts have a tradition.

The selected age threshold for old-age was traditionally set at age 60, but nowadays age 65 is often selected in advanced countries, moving broadly in parallel with the standard retirement age in public pension schemes. The starting age into the active population was historically 15 years, but is nowadays often replaced by the age of 20 in advanced countries. These choices influence the magnitude of measures (a) to (c), but have limited bearing on their dynamics.

Figures $2 a-2 f$ offer a glimpse of the dynamics of the aging population measures for the key regions of the world (left panels) and for the countries in East Asia (right panels) for the period 1950 to 2100 . To focus on the differences in the dynamics (not the levels), the measures for the number of the elderly are presented as an index, with the year 2000 chosen as the base. 
Figures $2 a$ and $2 b$ highlight the strong growth in the number of elderly throughout the world, with the dynamics inverse to the development level of the region (left panel) and the dynamics in the countries in East Asia related to their projected population growth (right panel), with the Philippines and Malaysia in the lead. These figures indicate that the growth of those aged $85+$ is expected to be about four times as high as for the population $60+$.

Figures $2 \mathrm{c}$ and $2 \mathrm{~d}$ signal the pronounced changes in the population structure, with the growing share of elderly in the population projected to concern all world regions and all countries in East Asia. Within 100 years, the East Asia region exhibits a projected shift of the elderly 60+, from some 10 percent in 2000 to over 40 percent by 2080 before slightly declining. The increase is even higher for countries such as China, Hong Kong, Korea, Singapore, and Vietnam. The development is similar but the change in levels is even more pronounced for the share of elderly 85+. Starting below 1 percent in 1990 (before which the data for this group were not universally collected), this share is projected to reach over 8 percent within 100 years in Hong Kong, Korea, and Singapore.

Figure 2e highlights the projected dramatic change in the OADDR (60+/15-59) for all world regions as well as for countries in the East Asia region. Again, the strongest change worldwide is projected for East Asia, moving from below 20 percent in 2000 to over 90 percent by 2100; within the region, the ratio for Korea and Singapore is projected to reach 120 percent by 2060 . Taken at face value, the latter value would mean that each active population member has to care for 1.2 elders. 
Figure 2a: Number of Elderly $(60+)$ Index $(2000=100)$
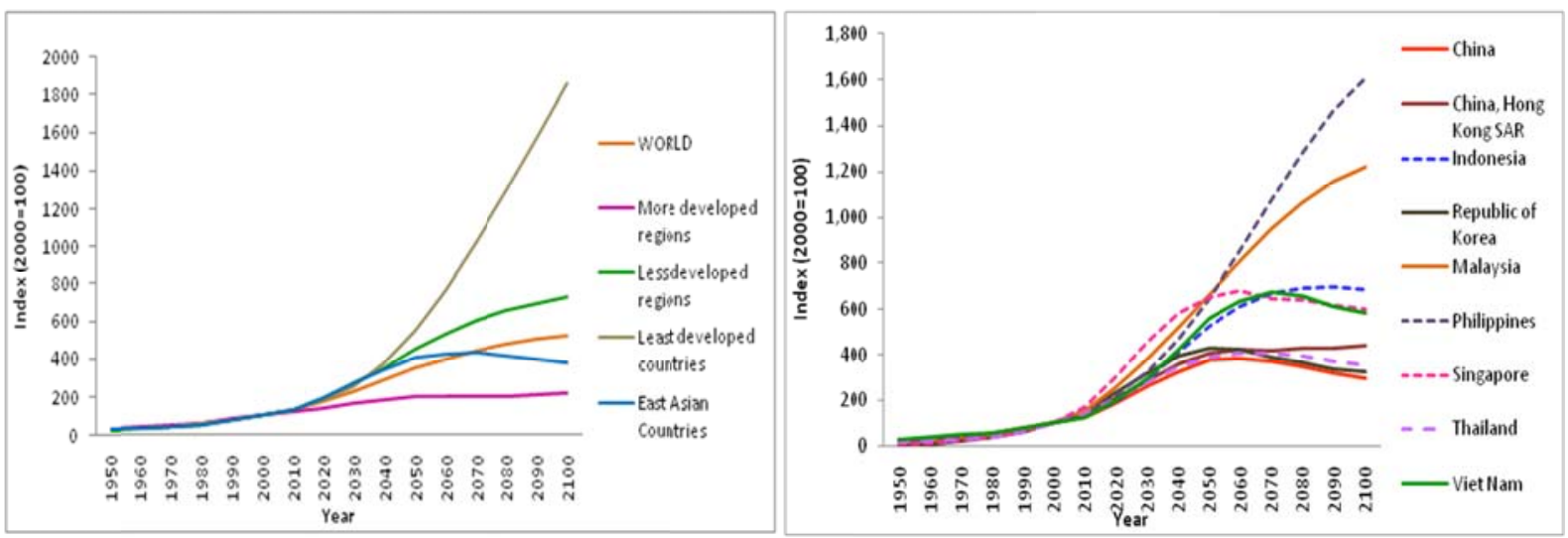

Figure 2b: Number of Elderly (85+) Index (2000=100)

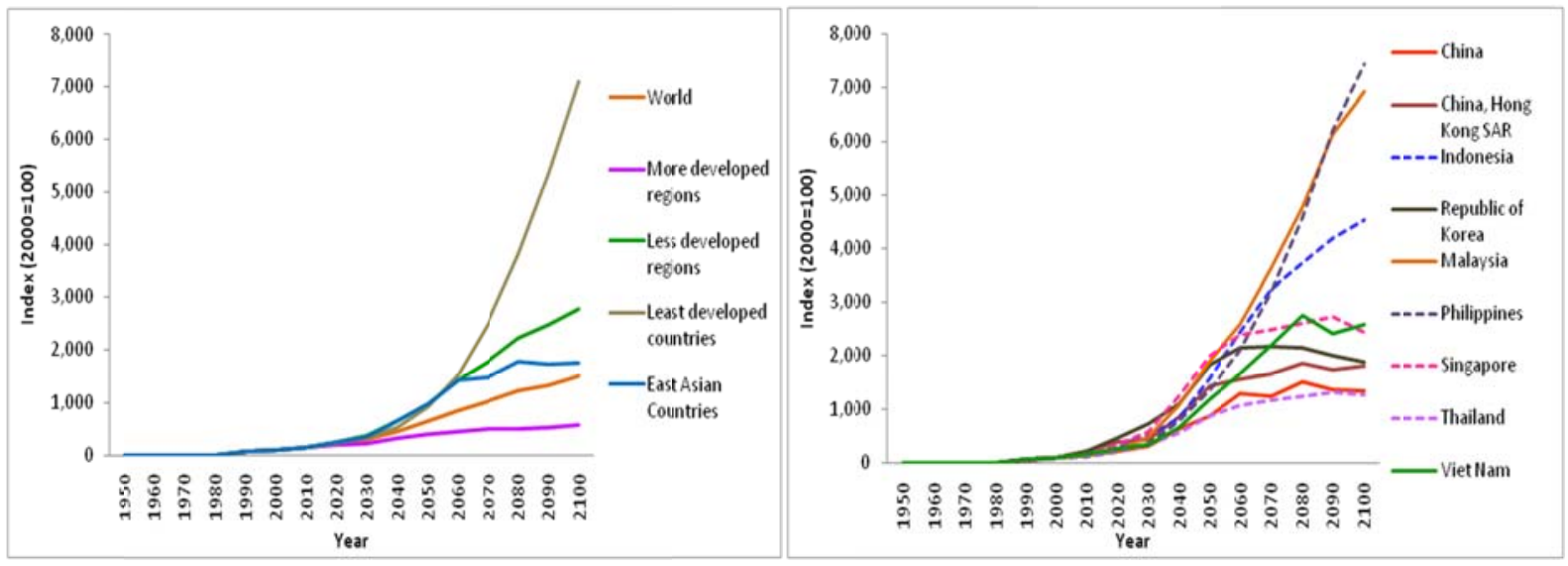

Figure 2c: Share of Elderly (60+) in Population (\%)

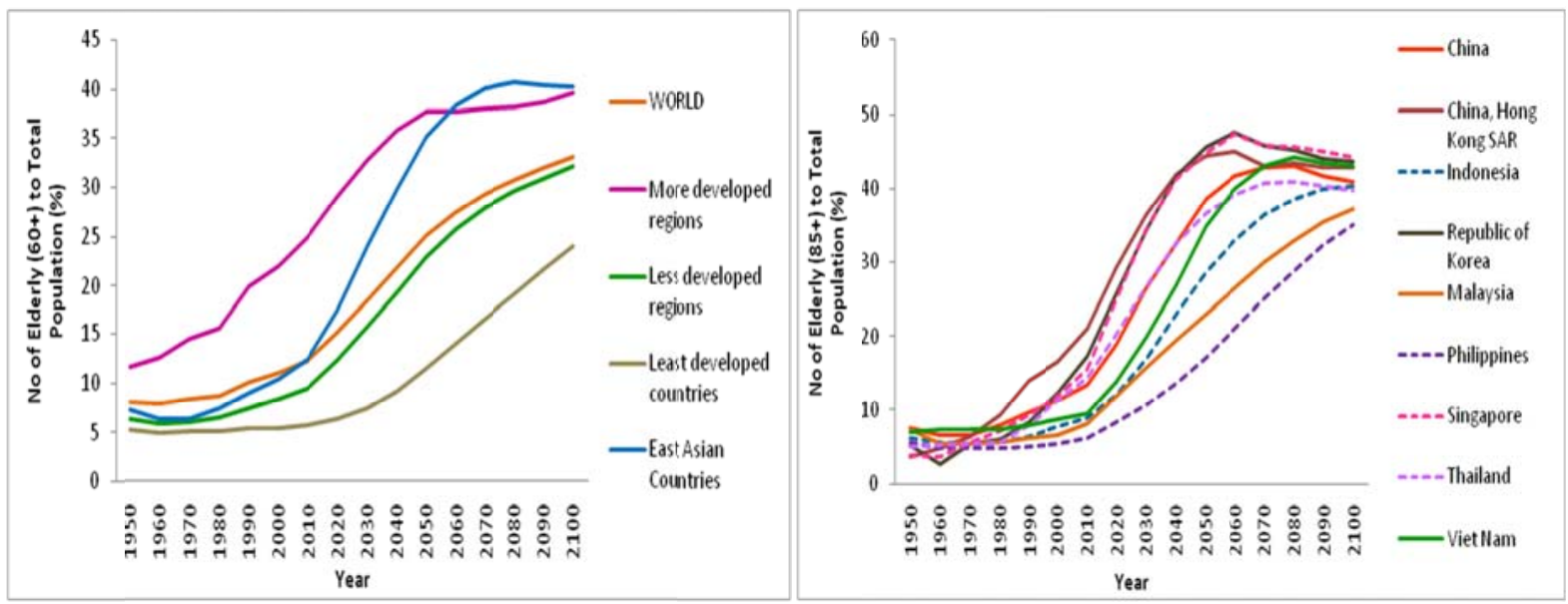


Figure 2d: Share of Elderly (85+) in Population (\%)
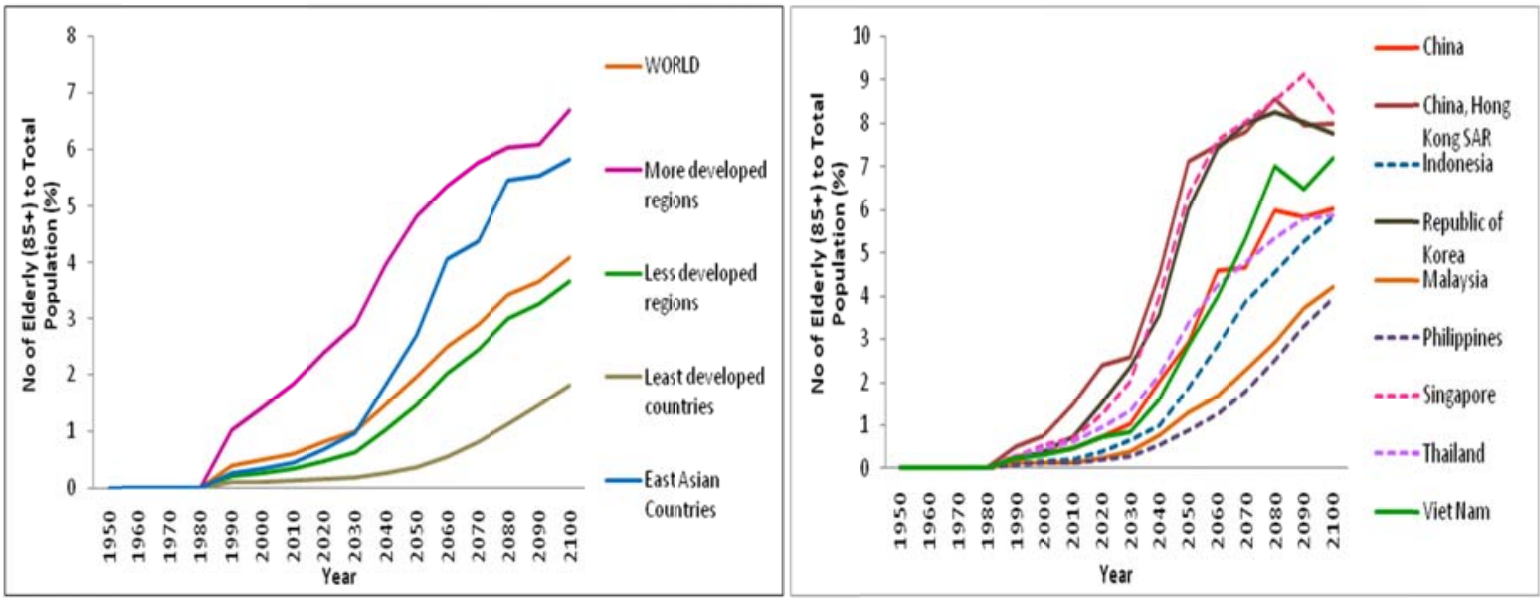

Figure 2e: Old-Age Dependency Ratio (60+/15-59)

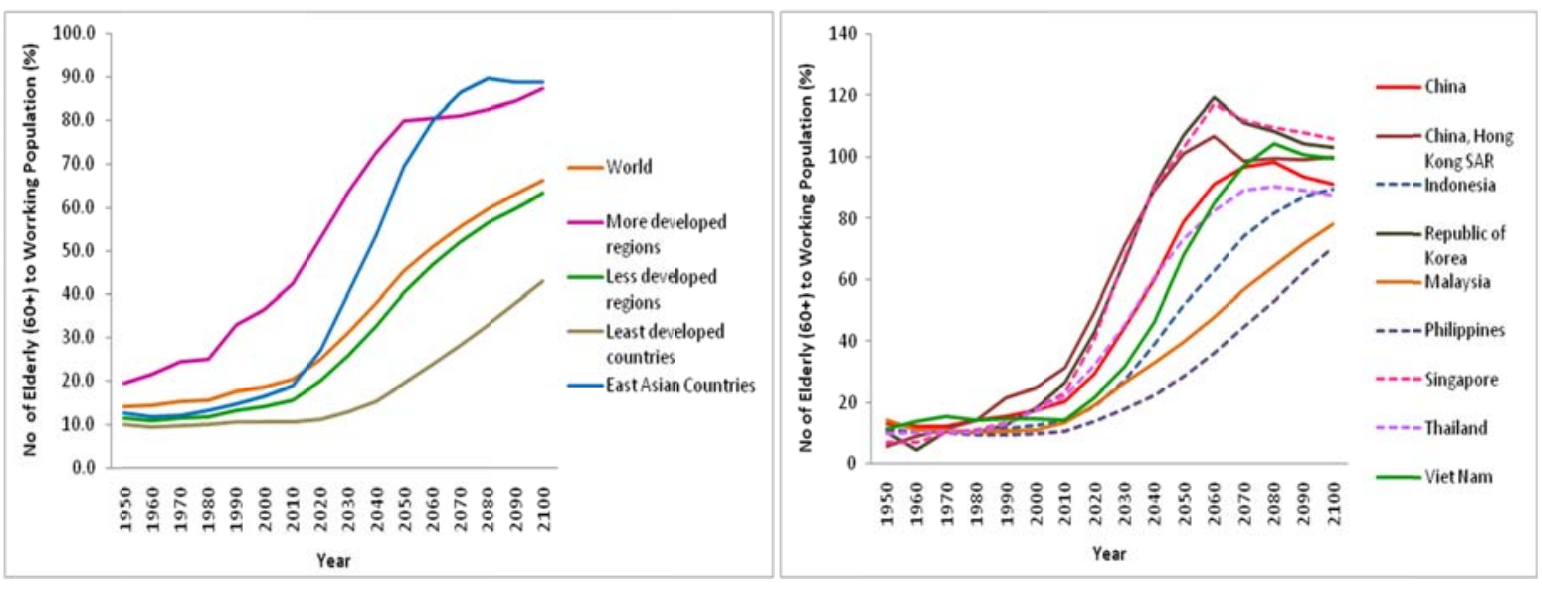

Figure 2f: Median Age of the Population

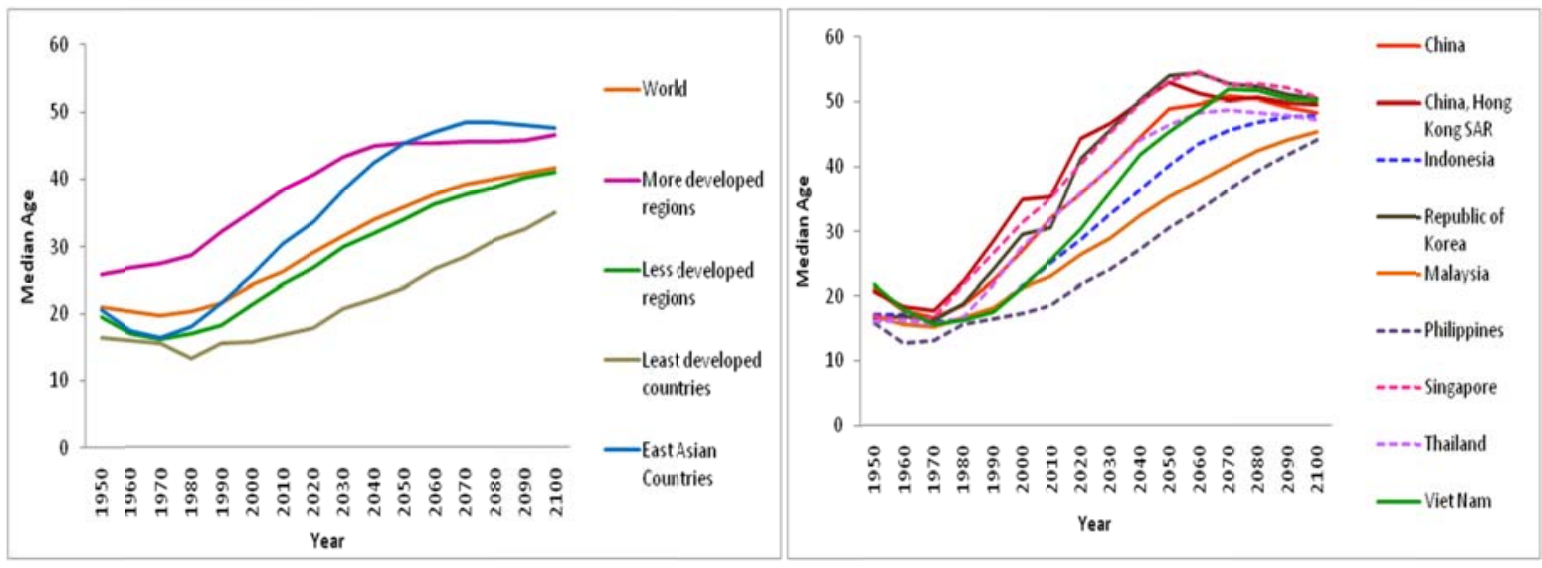

Source: Author's calculations, based on United Nations 2011 data and projections (UN 2011). 
The three drivers of population aging are broadly but not fully the same across regions and countries: aging from above (life expectancy), aging from below (fertility rates), and aging from across (migration flows). ${ }^{3}$ The specific origin of aging matters, as it has a bearing on the economic and other outcomes of a country.

(a) Aging from above refers to the increase in life expectancy triggered by the reduction in the mortality rate across all ages. But as the mortality rates at younger ages are getting very small, any further increase in life expectancy is (asymptotically) triggered by a mortality reduction/increase in life expectancy at higher ages (Eggleston and Fuchs 2012). Assuming a fertility rate at replacement level (decreasing toward two children per woman of reproductive age as mortality rates get very small), all population aging however measured comes from this source, with population at each age group growing, in particular at the higher age group. The honeycomb age pyramid grows upward with almost vertical slopes. As a result, and for a fixed activity span (say from age 20 to 65), an only slightly growing workforce would have to take care of an increasing number of non-active elderly people.

(b) Aging from below refers to the reduction in the fertility rate from higher to lower levels. Assuming a constant life expectancy and zero migration, all population aging - however measured - would come from this source. The fertility reduction narrows the base of the population pyramid during the long transition, creating a bulge that moves through the ages. If the fertility rate reduction stops at reproduction level, a honeycomb age pyramid would again emerge, and would not grow in size. If the fall in the fertility rate stops below reproduction level, the overall population size would shrink and a bulged honeycomb age pyramid of shrinking size would emerge until the population vanished. As a result, and for a fixed activity span, a shrinking workforce would have to take care of a non-active older population that shrinks less quickly.

In an average OECD country, aging from above and from below currently contribute in broadly equal shares to population aging, and a number of East Asian countries are moving in this direction. For the time being it is claimed that population aging in Asia is largely driven by aging from below (Lee, Mason and Park 2012).

(c) Aging from across refers to the effects of migration on the population structure. The effect is similar to changes in the fertility rate but typically takes place at the entry or exit age to the labor market. Migrant-sending countries age while the migrants stay abroad and will age again if the migrants return home for retirement (assuming in both cases that migrants are young when arriving and older when departing). For migrantreceiving countries, the opposite will happen: they rejuvenate while receiving and while sending back migrants. However, the economic effects may not follow the same pattern. If migrants send back remittances, the migrant-sending country will have an increase in national income. If migrants return with fully portable social benefits, the deteriorated demographic structure would not lead to an increased social budget burden (and the social budget burden in the former receiving (now resending) country would not be reduced).

\footnotetext{
${ }^{3}$ I take responsibility for these three notions as convenient shortcuts for the aging discussion.
} 
The above discussion has already indicated the key economic concerns with population aging, for which the concerns are essentially threefold:

(a) The distribution of the economic pie: With population aging under constant activity spans, the share of the non-active old to active population increases, leading to a deterioration of the old-age dependency ratio. This means that a smaller share of the (active) population has to take care of a rising number of non-active people, requiring redistribution of the economic pie in favor of the latter. With aging from above, the distribution occurs only from the active to the old-age population. With aging from below, some redistribution from the shrinking share of youth to the expanding share of elderly can take place. A key approach to address this policy concern consists of extending the activity span, which is also proposed from a revisited population aging angle (discussed in sub-section ii).

(b) The growth of the economic pie: Aging from below reduces the inflow of youngsters into the labor market in relative and absolute terms. As they are expected to enter the labor market with the latest knowledge, new skills, and entrepreneurial drive, there is fear that innovation, and consequently productivity and economic growth, will suffer. Compensating for the lower inflow into the labor market through a reduced outflow (i.e., an expanded activity span) may not do the trick either if older workers do not bring the same capabilities to the table. Yet it is conceptually and empirically still unclear if, by what means, and by how much economic growth may be reduced by population aging, and it is also not clear by what policy measures a growth impact might be effectively addressed (discussed in sub-section iii).

(c) The impact on the rate of return: Both funded and unfunded social programs have an underlying explicit or implicit rate of return that is potentially impacted by population aging. In unfunded social programs (such as for pensions or health), the implicit rate of return is, in the steady state, the rate of wage growth per capita (i.e., labor productivity growth) plus the growth in labor force, and both are directly affected by population aging. In funded social programs, the rate of return is the market interest rate, which may also be negatively affected by population aging as it shifts the population share from saving to dissaving cohorts (at least under life cycle considerations). A lower rate of return means that individuals would have to save more to achieve the same target benefit level. Both rate of return effects are closely related to economic growth effects but exhibit separate features (discussed in Section 4).

These concerns are real and to be taken seriously but need not necessarily be realized as projected since population aging builds on dynamics that may allow full or at least partial compensation or counteracting actions.

\section{(ii) Population Aging - Revisited}

An aging population is much less of a concern if it results from an increase in life expectancy or a fall in mortality rates that occurs in parallel with reduced disability and morbidity, and with increased cognitive skills. The available data offer indications for all three of the latter, and strongly suggest that the current indicators for aging are misleading and should be replaced or at least adjusted. 
Rising life expectancy suggests that defining age only retrospectively (i.e., by the number of years lived to date) may be a misleading indicator. What matters more nowadays is prospective age (i.e., the number of years from the current age to the expected death or the current age adjusted for remaining life expectancy), a concept proposed by Sanderson and Scherbov (2007). The following example gives a gist of the adjustment to undertake:

- An Australian man aged 62 in 2000 has the same remaining life expectancy as a 54-yearold in 1950 (19.6 years).

- A French woman aged 40 in 2005 has the same remaining life expectancy as a 30-yearold in 1952 (44.7 years).

Hence, after choosing an anchor year, one is able to adjust the (retrospective) median age of a population with the projected period or cohort life expectancy to get the prospective median age. Such an adjustment is undertaken in Figure 3 using U.S. population data. The surprising result is that while the retrospective median age exhibits a major increase, the prospective median age actually decreases slightly; i.e., the U.S. population is projected not to age but to rejuvenate.

Using this prospective age concept, one can also redefine the Old-Age Demographic Dependency Ratio by taking the adjusted prospective age to define the increasing activity span. Table 1 offers comparative calculations for Germany, Japan, and the U.S. The conventional OADDRs in the right column mirror the development presented in Figure 2e, signaling a drastic rise over the next decades. Adjusting the upper age of the retirement span of 65 in 2000 in line with the increase in the prospective retirement age leads to an age well beyond 70 in all three countries by 2050 (right column). Using this adjusted age to calculate the OADDR leads to increases in this aging measure that seem much more manageable (middle column).

Doing such an exercise for all European countries and comparing the conventional and prospective old-age dependency ratios for 2030 provides a totally different perspective on the challenges. Under the conventional measurement, Western Europe, and in particular Germany and Finland, exhibits the highest increase. Under the prospective view, it is the former transition economies in Eastern Europe, from Belarus to Bulgaria and Romania, that exhibit the highest increase as the low fertility rate and low increase in life expectancy superimpose. Due to the projected further and strong increase in life expectancy, Western Europe looks almost fine (see Vienna Institute of Demography 2013).

There are an increasing number of other adjustments proposed in the literature to take account of positive changes in aging populations that go hand in hand with the reduction in mortality rates across ages, notably a reduction in disability rates, a reduction in morbidity rates, and improvements in cognitive capacity (see, for example, Skirbekk, Loichinger and Weber 2012). Translating these improvements into adjusted dependency ratios points to the same conclusion: traditional measures of population aging grossly exaggerate the scope of aging and need to be adjusted. A critical adjustment is needed for the indicator of the age of the onset of aging/termination of working activity to take account of the increase in the many 
healthy years thereafter.

Figure 1 US: Median Age and Prospective Median Age Computed with Period and Cohort Life Tables, 2000-2050, Based on the Assumption that Life Expectancy at Birth Increases by 0.2 Years per Calendar Year

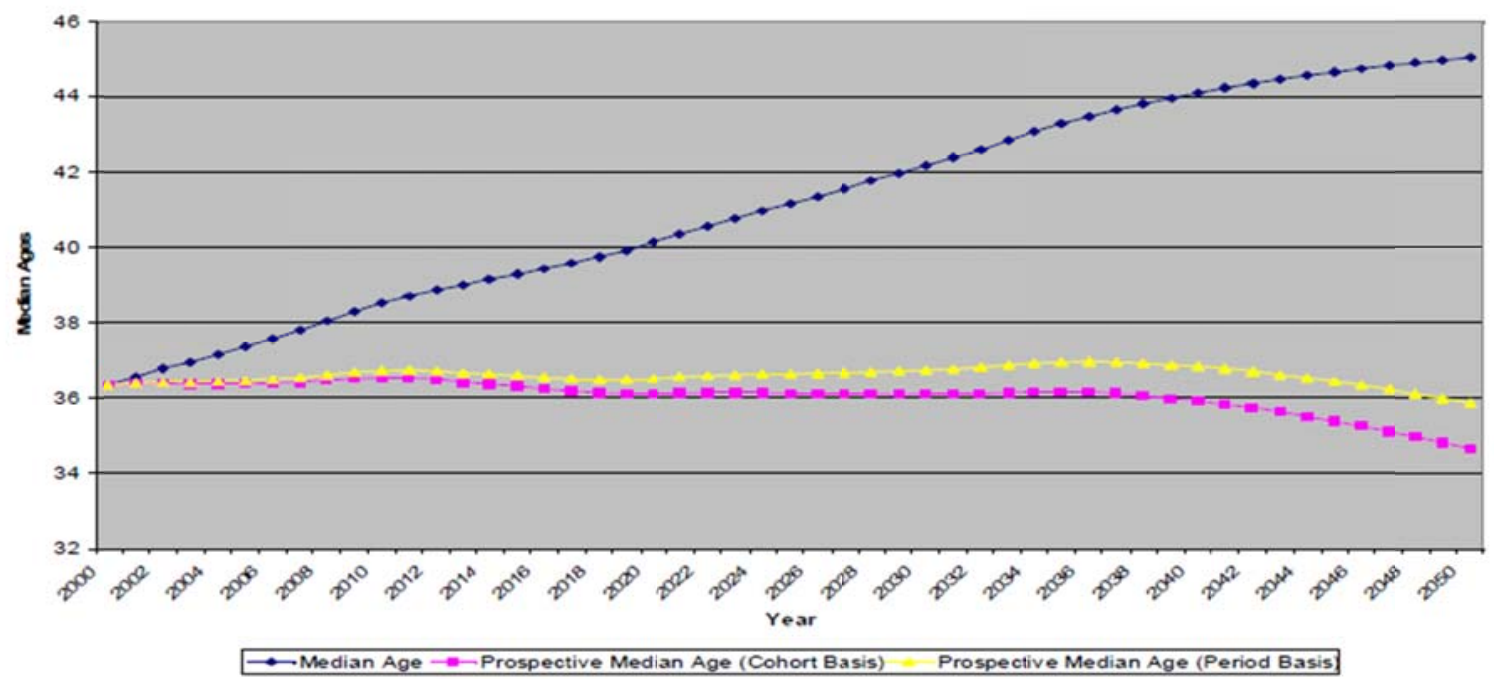

Source: Sanderson and Scherbov 2007.

Table 2: Age at the onset of "Old Age Dependency", prospective old age dependency ratio, and the conventional old age dependency ratio, Germany, Japan, and the United States at ten year intervals from 2000 to 2050

\begin{tabular}{llll}
\hline & $\begin{array}{l}\text { Age at the Onset of } \\
\text {-Old Age Dependency } \\
\text { (Prospective Age = 65) }\end{array}$ & $\begin{array}{l}\text { Prospective Old Age } \\
\text { Dependency Ratio }\end{array}$ & $\begin{array}{l}\text { Conventional Old Age } \\
\text { Dependency Ratio }\end{array}$ \\
\hline Germany & 65.0 & 0.261 & 0.261 \\
2000 & 66.7 & 0.295 & 0.335 \\
2010 & 68.4 & 0.283 & 0.375 \\
2020 & 70.1 & 0.310 & 0.504 \\
2030 & 71.8 & 0.377 & 0.609 \\
2040 & 73.4 & 0.369 & 0.650 \\
2050 & & & \\
Japan & 65.0 & 0.276 & 0.276 \\
2000 & 66.6 & 0.334 & 0.3818 \\
2010 & 68.1 & 0.419 & 0.576 \\
2020 & 69.6 & 0.423 & 0.729 \\
2030 & 71.2 & 0.436 & 0.866 \\
2040 & 72.8 & 0.507 & 0.199 \\
2050 & & & 0.203 \\
United States & 65.0 & 0.199 & 0.265 \\
2000 & 66.3 & 0.183 & 0.346 \\
2010 & 67.7 & 0.205 & 0.377 \\
2020 & 69.1 & 0.247 & 0.399 \\
2030 & 70.5 & 0.258 &
\end{tabular}

Source: Sanderson and Scherbov 2007. 


\section{iii) Population Aging and Economic Productivity - A Dynamic View}

Lengthening the activity span of individuals to take account of the increasing life expectancy is thus the way to rebalance demographic structures. But will such a mechanical adjustment also lead to the expected economic rebalancing? Will the productivity of a country nevertheless not decline as its population ages?

The background for concern or optimism regarding productivity changes in an aging population centers on the following three developments:

(a) The decline of capabilities with age that starts early on and covers most faculties, as presented in Figures $4 \mathrm{a}$ and $4 \mathrm{~b}$. Figure 4a suggests that everything except experience decreases with age and even experience levels off at a young age. Managerial ability remains constant throughout individuals' working age (after a small increase at young age). All other skills linked with cognitive and physical abilities decrease early on and sharply. Translating these trends of rising experience in the early part of active life and decreasing abilities around the age of 25-34 to productivity effects gives rise to the typical hump-shaped productivity-age profile depicted in Figure $4 \mathrm{~b}$. Linking such a productivity profile with an aging population structure that moves the population gravity to higher ages must numerically reduce macroeconomic productivity (i.e., output per person employed). The cross-country evidence of a negative link between a change in the work force composition and total factor productivity is strong and significant (for OECD countries, see Feyrer 2007) and is increasingly a concern for countries in East Asia (see, for example, Phang 2011 and Thang 2011).

Figure 4a: Skills and Age

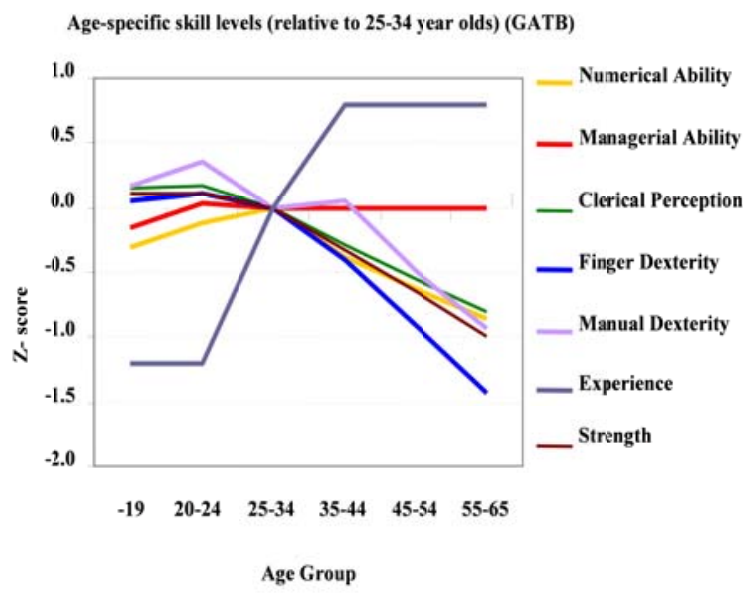

Source: U.S. Dept. of Labor 2007.
Figure 4b: Productivity and Age

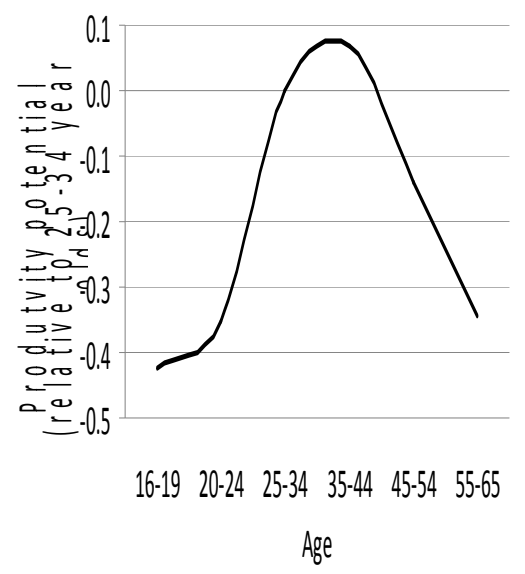

Source: Skirbekk 2008.

However, concerns about the size of the fall in abilities with age or even its direction are not shared by all. For example, Van Ours (2010) measures physical productivity and cognitive ability across ages and finds some reduction but it is relatively mild. Similar estimates of age profiles of productivity and wage costs for the Dutch industry indicate moderate age effects that may actually reverse, resulting in a rising 
productivity profile if accounting for time-invariant differences between firms and the potential endogeneity of the old-age structure of firms (detailed in Van Ours and Stoeldraijer 2010). While the latter results may raise technical questions, in general, the micro-effects of aging and productivity are not well researched or established as of yet. Furthermore, productivity levels across ages are not exogenous and are thus open to policy interventions (Ilmakunnas et al. 2007). A 2013 supplement of Labor Economics (the official journal of the European Association of Labour Economists) contains seven recent and innovative papers on the topic of "Ageing and Productivity," with mixed results that offer some optimism but do not support any complacency. ${ }^{4}$

(b) The important dynamic effects that need to be taken into account when investigating the link between age(ing) and productivity. The suggested negative impact emerges from linking a constant age-productivity profile with an aging population profile that results from lower fertility (i.e., fewer children), and higher life expectancy linked with more healthy years at higher ages. Yet having fewer children allows one to give more attention to their education and skill development, which may result in higher productivity at any given age ${ }^{5}$. Increased life expectancy also increases the planning horizon and thus lengthens the amortization period of individual and public education expenditure, which should further increase human capital investment and thus productivity outcomes. And healthier and longer lives should also positively affect the cognitive abilities of individuals across the age spectrum.

These considerations are consistent with the results of country panel studies and the differences across countries in their progress in aging. For example, Figure $5 b$ presents the cognitive abilities of Swedish cohorts that are 25 years apart. For both groups of cohorts, there is a significant decrease in ability with rising age. However, the results also suggest significant progress in all ability categories for younger cohorts, albeit with differences between the categories. Major changes between cohorts are suggested for verbal and memory abilities, for example, making somebody aged 78 in the younger cohort as able as somebody in the older cohort but at a much younger age. Figure $5 b$ presents estimates of productivity potential across different countries. The results for the U.S. and Northern and Central Europe give hope that less advanced countries will flatten their productivity profile with progress in secondary education, but the results for Southern Europe also indicate that progress is not automatic.

Building on a continued improvement of cognitive abilities for the young and older population Skirbekk et al. (2013) can demonstrate continued cognitive improvements among successive cohorts of older adults. With projections based on different scenarios for cognitive cohort changes as well as demographic trends they show that if the Flynn effect observed in recent years continues, it would offset the corresponding age-related cognitive decline for the cognitive abilities studied. In fact, if observed cohort effects should continue, their projections for the UK show

\footnotetext{
${ }^{4}$ See Bloom and Souza-Poza (2013) for a on overview of these papers.

${ }^{5}$ The idea of a quantitative-qualitative trade-off goes back to Becker, Lewis and Willis (1973). For a literature review see Lee and Mason 2010b, for recent results Prettner, Bloom, and Strulik 2013
} 
improvements in cognitive functioning on a population level until 2042-in spite of population aging.

(c) Microeconomic results about progress in productivity with each younger cohort may provide hope for the economic growth impact of population aging, but empirical evidence is lacking. The empirical outcome from such a dynamic vision is uncertain and (to the author's knowledge) has not yet been empirically established. Traditional results based on cross-section estimation and projections are sobering. Cross-country econometric evidence for 115 countries suggests that the share of the elderly population has a statistically significant impact on growth of real GDP per capita (IMF 2004: table 3.1). Using the coefficient from this research and the demographic forecast for advanced economies suggests a reduction in the annual real growth rate of GDP per capita of 0.5 percent, on average, by 2050 -that is, per capita growth would be 0.5 percent lower than if the demographic structure had remained unchanged. This does not sound like a lot, but could actually reduce the expected rate of technical progress for mature economies (about 1 to 2 percentage points) by some 25 to 50 percent.

Figure 5a: Cognitive Abilities in Two Cohort
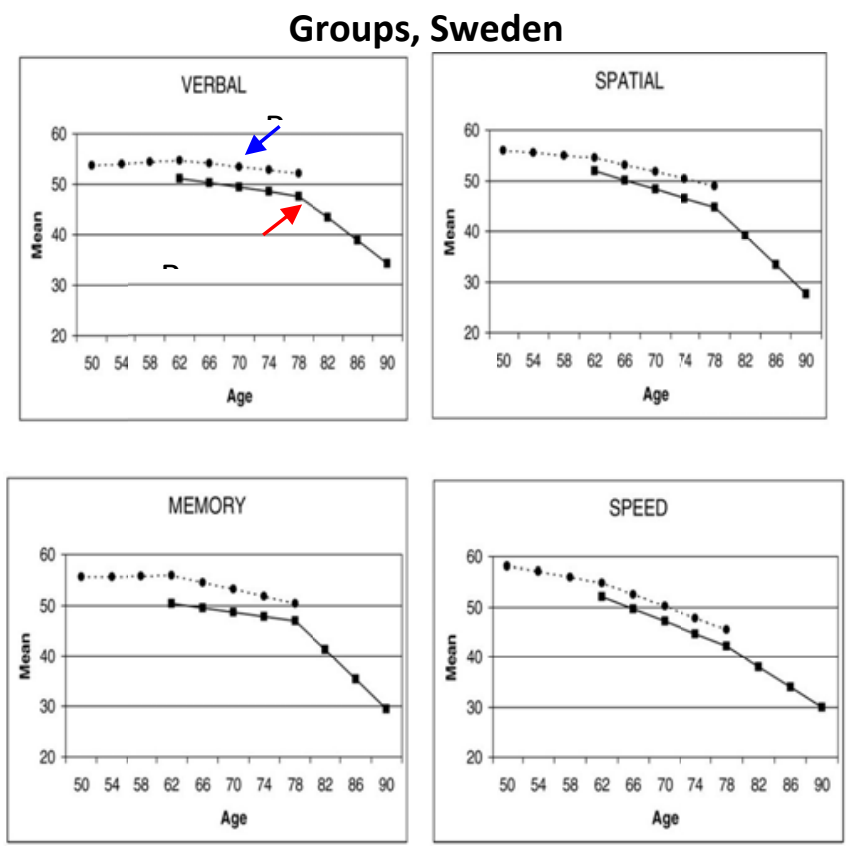

Source: Finkel et al. 2007.

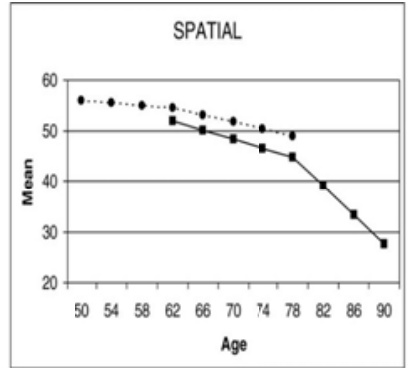

Figure 5b: International Variation in Productivity Potential - Secondary Education, 2005

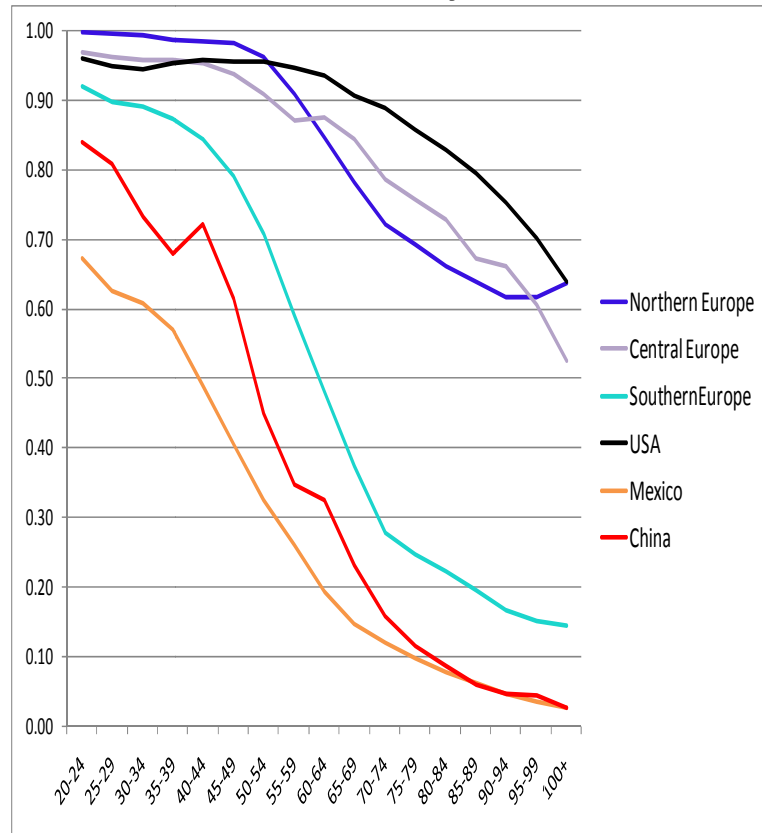

Source: IIASA estimates, mimeo.

The messages from Section 2 offer optimism along two dimensions:

First, one should not be misled by the traditional measurement and projections of population aging: they need to be reviewed and revised, particularly with regard to the onset of what is considered "old." Second, one should not be afraid of the traditional view and results on population aging and productivity: there is reason for (some) optimism. 
However, the key messages from the next two sections call for caution as salvation does not come automatically: countries need to have appropriate policies in place to be able to address population aging well.

\section{Critical Policy Paths to Address Population Aging}

This section proposes and outlines five critical policy steps at the micro- and macroeconomic levels to make population aging satisfying for individuals as well as successful in societal and economic terms. In this section, I offer my personal take on the policy areas that need to provide good answers to the following questions:

(i) What is required for individuals to age happily?

(ii) What is required to cope with the economic implications of population aging?

(iii) What is required to focus the mind of society and policy makers on paradigm shifting reforms?

(iv) For which policy areas do baseline scenarios of economic implications need to be developed?

(v) How can the most appropriate policy responses to address population aging be identified?

A very brief discussion of these areas and the proposed solution paths serves to prepare the discussion on the choice among old-age financial protection schemes (the subject of Section 4).

\section{(i) What is required for individuals to age happily?}

At the center of any policy selection should be the welfare of the individual, and the selected policies to address population aging should to be consistent with this individual welfare perspective under changing demographic and economic conditions. This raises questions that go well beyond mere economic considerations, in particular: What is required to age happily? The growing number of elderly has increased the number of answers to this end, covering a large set of topics intended to help one improve happiness and health in one's old age. ${ }^{6}$

The quest for happy (or successful) aging has a long tradition that goes back more than 2000 years, ${ }^{7}$ and the list of conjectured ingredients from medical and social science studies is long. ${ }^{8}$ The notion of successful (versus happy) aging is preferred by some researchers as it is triggered by fulfilling specific criteria, such as passing a certain age limit, being in good health and spirit, enjoying autonomy of living, etc., but there is no consensual definition of the triggers to be included. Happiness in these studies is often a starting condition for successful aging. My preferred notion of happy aging is quite likely a bit vaguer and open to many alternative ingredients but may have higher aspiration, as it linked to the conditions of being broadly healthy and happy and having a positive outlook on life every day.

\footnotetext{
${ }^{6}$ The biggest NGO worldwide for the elderly, the U.S. American Association for Retired People (AARP), offers in its bi-monthly bulletin articles and advice to this end. See, e.g., AARP Bulletin Vol. 54/No. 1 of January-February 2013 for "10 Tips for Better Health."

${ }^{7}$ Cicero's (44 BC) essay De Senectute (“On Old Age") falls into this camp (see Rowland 2009) and there are certainly similar Asian elaborations that could be quoted if known to me.

${ }^{8}$ For a small but relevant selection see, e.g., Erdman 1979; Fisher 1995; Bowling and Dieppe 2005; Franklin and Tate 2009; and Pruchno, Wilson-Genderson and Cartwright 2010.
} 
The ingredients for happy aging proposed by the medical and social science literature are many, with focus and priorities not independent of the angle of the researcher. The following priority listing reflects my own selection of key ingredients and their empirical relevance as established from the very large literature. It borrows from an article I read some time ago that I can no longer retrieve, and favors ingredients that constitute inputs resulting from one's own actions, not exogenous events:

1. Have a purpose in life that is on your mind when you rise and get ready for the day. This can be a paid or unpaid job, a hobby, or another occupation that makes life worthwhile.

2. Do physical exercise, preferably every day and as best as you can, and enjoy it. Such exercise helps one to stay healthy, reduces stress, and is a natural fountain of lifelong youth. A healthy life-style strengthens the outcome.

3. Stay socially embedded through family, friends, or other forms of social interaction, as these established psychological mirrors are critical for wellbeing.

4. Take care of the "birds and the bees," as this is a major part of one's humanity throughout life.

Of course the first item listed for happy aging - a purpose in life, such as a job -has a major bearing on decisions regarding how to address the fiscal implications of population aging and the choice of retirement schemes and policy parameters.

\section{(ii) What is required to cope with the economic implications of population aging?}

The analysis in the prior section suggests an easy way to address population aging and its economic implications: (a) handling the impact of population aging on the distribution of the economic pie requires an adjustment in the activity span through longer work/later retirement; and (b) handling the impact of population aging on the growth of the pie requires assuring that the productivity of an older workforce continues to also increase. The key necessary conditions for this are proposed to be threefold and require keeping individuals:

1. Healthy

2. Skilled, and

3. Motivated to work longer.

While these necessary conditions are easily stated, it is more difficult to identify other necessary conditions that need to be met. They are likely to include a change in mindset and a revision of societal institutions, as discussed next. And while the conditions of keeping individuals healthy, skilled, and motivated to work longer are easily pronounced, the relevant knowledge and quite likely the policy interventions to make this happen (or even to initiate nudging in this direction) are currently largely missing.

\section{(iii) What is required to focus the mind of society and policy makers?}

Society in general and policy makers in particular need to understand that population aging is quite likely the most important change to mankind in the last 10,000 years. For the purposes of this paper, the dramatic changes that have taken place during the last 200 years or so are the most relevant. Until the end of the $18^{\text {th }}$ century, life expectancy had been essentially constant since the time of the hunter-gatherers (Burger, Baudisch and Vaupel 2012). Their mean life span at birth was around 31 years; for Swedes, it was about 32 years in 1800, 52 years in 1900, 
and 82 years today. ${ }^{9}$ Thus, since the early 1800 s, the life expectancy of an adult (say at age 20) has more than tripled in advanced countries, with most progress in the last century, and growth has continued in a linear fashion (Oeppen and Vaupel 2002) that has totally changed the outlook on life for everybody (Juvin 2005).

As a consequence, the actions needed to adjust to this dramatic change must go well beyond a few parametric changes or even major reforms in public programs. Population aging calls for a review and revision of all social-economic institutions as we know them. As a starting point for calling for a comprehensive and drastic revision, one needs to recognize that societal institutions were not made for such a long and continuously expanding life span and are not yet prepared for this change. This includes quite likely the oldest institution of mankind - marriage.

For thousands of years, the mean length of a marriage was about 10 plus years, as the husband was likely to be killed in a battle or similar event, and the wife likely to die in childbirth. Nowadays, abstracting from late marriage and early legal separation (divorce), the mean length of a marriage could be 50 or 60 years, with rising tendency. But as the increasing phenomenon of patchwork families across the globe demonstrates, the reality is different, and most countries nowadays admit and experience multiple divorces, have added new institutions such as partnerships, and more changes are likely to come.

Similarly, the much younger institution of retirement needs to be reviewed and revised, as do many other societal institutions, public policies, and programs. Business as usual is not helpful, to put it mildly. Society and policy makers need to understand the uniqueness and scope of the dramatic demographic shift that must now be accommodated.

\section{(iv) For which policy areas do baseline scenarios of economic implications need to be developed?}

A useful approach to motivate policy makers, to inspire researchers, and to help conceptualize the issues and possible solutions to a problem is the elaboration of the economic (and possibly other) implications under a baseline scenario. In the simplest approach, one takes the main plus a few alternative aging scenarios over a relevant period of time (say 50 or 100 years) and elaborates on the economic implications under a current policy scenario (i.e., unchanged economic and other policies). A review of the burgeoning aging literature offers inspiration and many hints. The value added is to conceptualize and structure the implications and to triage them by importance, priority, and timing.

A suggested starting point for such an exercise is a review of three key areas: the central macroeconomic implications; the implications for markets; and the implications for public policies and programs. The following sketches the key headlines:

Central macroeconomic implications, including those touched upon in the prior sections, such as the impacts of population aging on:

- Productivity profiles and thus productivity growth and hence the future size of the output pie

- The redistribution of the output pie due to shifts between the active and nonactive populations (including a smaller share of youth)

\footnotetext{
${ }^{9}$ Human Mortality Database. Available at www.moratlity.org/.
} 
- The rates of return for unfunded and funded insurance programs such as pensions and health and the implications for benefit level and financing (see, e.g., Holzmann 2009)

Implications for key markets, in particular, the impacts on:

- The output market (for public and private consumption and investment)

- Labor and financial markets (due to major shifts in supply and demand)

- Other key markets, such as property markets, the health market, etc.

Implications for public policies and programs, in particular, the impacts of population aging on:

- The financing of public and private pensions, health care, long-term care, education, labor market programs, etc.

- Expenditure programs such infrastructure, defense, rural areas, etc.

- The scope and composition of tax and other public revenues

For a number of these issues, international organizations such as the ILO, the IMF, OECD, the UN, and the World Bank have undertaken worldwide and regional studies over recent years or even decades that offer guidance and inspiration. ${ }^{10}$ However, for data reasons, they typically focused on the macroeconomic/aggregate aspects, and now need to be deepened and substantiated at the country level and key markets.

(v) How can the most appropriate policy responses to address population aging be identified? If and as issues emerge from the prior review, policy options need to be developed or identified across the board to address the adverse implications of population aging. A natural tendency for policy makers may be to fiddle with existing policies and programs and to suggest a few parametric adjustments. In light of the size and depth of change that population aging brings to the economy and society at large, such an approach is conjectured to be insufficient and even counterproductive. What needs to be done for all policy areas is to sit back and think deeply about the key issues and come forward with out-of-the-box proposals; at times, this knowledge is lacking, but issues and processes to this end need to be identified. The following illustrates this briefly with examples from health care and labor market policies.

Health care: The two key issues for health care programs (and their expenditure) in an aging society are:

- How to help people live a healthier life, as this would imply a shift of the age-health care expenditure profile to the right, compensating partially or fully for the demographic shift toward an elderly population (Figure 6a). Can such a shift toward a healthier life style with regard to nutrition, physical exercise, smoking, and drinking be achieved by financial or other incentives, or is it more effective to use propaganda and social marketing, regulation and enforcement, or a combination of all?

\footnotetext{
${ }^{10}$ A very incomplete and indicative list only includes IMF: Chand and Jaeger 2000; World Economic Outlook 2004, Chapter 3; World Economic Outlook 2012, Chapter 4; OECD 1998, 2005, 2012, and Holzmann 1988; and World Bank: Chawla, Betcherman, and Arup Banerji 2007; and Cotlear 2011.
} 
- Which health care system gives the highest "bang for the buck" and by what metric is this judged? Is it maximizing the length of life or the years of healthy life?

Figure $6 \mathrm{~b}$ illustrates the option between these two choices. The "scientific approach," driven by the ambitions of the medical profession and often the financial interest of health care institutions, seemingly caters toward prolonging life at all costs (reportedly an expensive approach) instead of letting elderly individuals die without merely life-prolonging interventions. A "welfare maximizing approach" may put the effort on reducing early death by focusing on prevention and fighting communicable and non-communicable diseases (reportedly a much cheaper approach). Such a fundamental discussion about policy choices gains in importance in an aging society and needs to be led, but may be difficult to engage in due to resistance by vested interests and reluctant policy makers.

Figure 6a: Shifting the Expenditure Profile

Figure 6b: Changing the Approach to Policy

Changing the Health Expenditure Profile ...

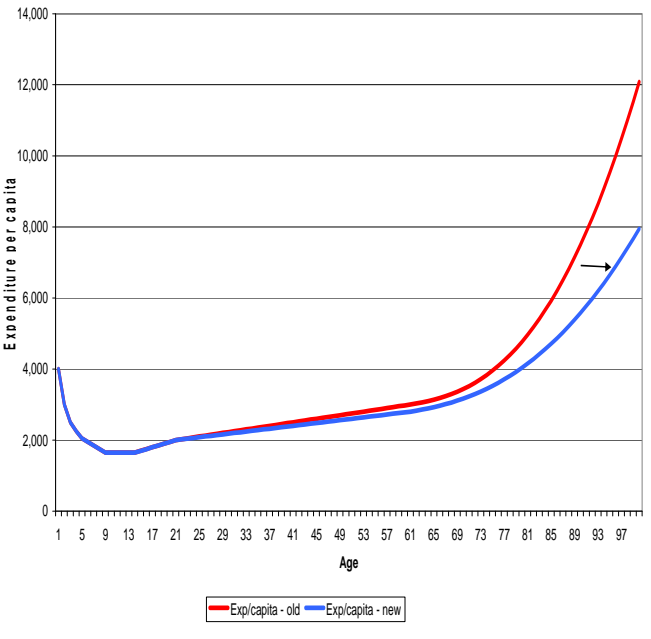

Source: Author.

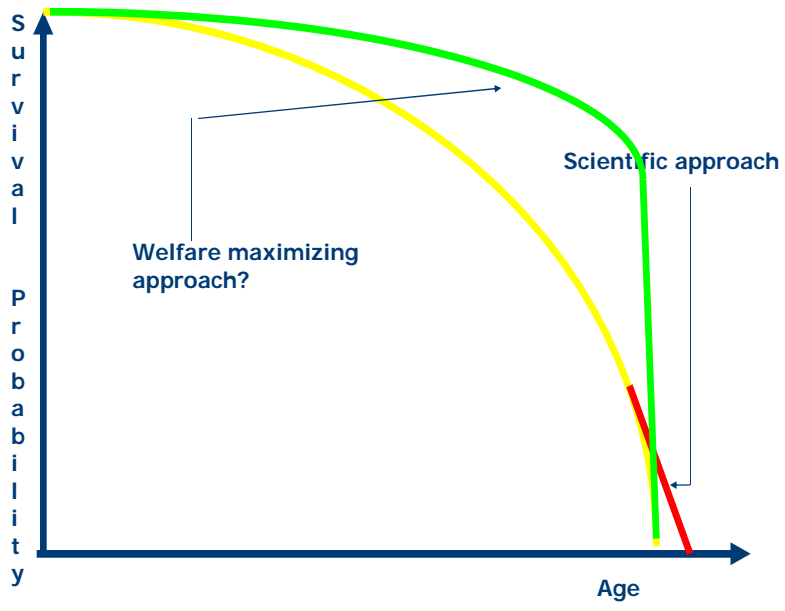

Source: Author.

Labor market and education: The understanding of issues and knowledge around population aging and labor markets is still limited, even in advanced economies, and where information is available, it is often not well shared. The following outlines the key issues and knowledge gaps I consider critical in this area to make population aging a successful country experience. They are summarized in three questions: ${ }^{11}$

- What are the incentives that will keep the elderly in the labor market? The answers may be seemingly simple, but the full set of interventions to make this happen is not yet

\footnotetext{
${ }^{11}$ For some elements of these questions and potential answers see, for example, OECD 2006, the papers in Holzmann et al. 2009, and Walker 2006. For proposals to measure progress in mainstreaming aging, see Marin and Zaidi 2007.
} 
known. To this end it may be instructive to distinguish between the supply and demand sides:

Supply side: Keep individuals healthy, skilled, and motivated (already mentioned above), but also provide a pension system that creates incentives to stay in a formal job (i.e., under pension coverage) during working life and at higher ages.

Demand side: Create incentives for employers to hire and/or keep the elderly employed, which requires, inter alia, a review of the seniority principle of pay but also of excessive firing protection for elderly workers.

- How to keep and upgrade the skills of elderly workers? Life cycle decisions for individuals and firms are faced with a high level of asymmetric information and uncertainty, which creates challenges for interventions such as:

Lifelong learning: This is a concept often alluded to and easily appreciated by all involved, but is little conceptualized in an operational and implementable manner, and hardly ever viewed from a dynamic labor market perspective.

Rethinking wage negotiations: As improved skills mostly profit the individual, the worker should bear most of the costs (although employers and the government also profit to some degree from the externalities of workers' better skills and should contribute to some extent). This calls for a revision of negotiations between workers and employers, convincing workers' representatives/trade unions to shift from demanding reduced working hours and higher wages to introducing requests for more training and skill acquisition into the negotiations.

- How to deal with changes in the capacity and skill mix of elderly workers? Whatever progress can be made at shifting the age-skill profile upward, the mix of skills is changing with age and needs to be accommodated by work assignments to the profit of all. Known (but often untested and little evaluated) approaches include:

Redefining the role of the elderly: Firms in advanced countries (such as Finland and Germany) have started to change the work process for the elderly on the production line or to move elderly workers into mentor positions for younger workers, with reportedly measurable success. ${ }^{12}$

Pre-retirement job change: For employees in enterprises and administration, retirement at the highest job level will need to become a feature of the past. But how best to accommodate such a change - e.g., through reassignment within the unit or changing to a new employer/self-employment - has yet to be explored.

If and how a country addresses these and other labor market-related issues and fills the knowledge gaps for support of an evidence-based policy will be the make or break point that determines whether or not that country successfully handles its population aging.

\footnotetext{
${ }^{12}$ See Ilmarinen (2005) for an early review of issues and Finish approaches, and read the success story on "BMW 2017" and changes made to the production line to support an aging labor force (Bauer and Mauermann 2010).
} 


\section{Population Aging and Selection of the Old-Age Financial Protection System}

The prior sections outlined the contours under which an old-age financial protection (i.e., oldage pension) system will operate under population aging and they highlighted areas and policy approaches conjectured to help make individual and population aging a successful experience. This section: (i) explores the key prescriptions of organizing consumption smoothing and labor supply under a lengthening life span; (ii) proposes criteria for the selection of an old-age income scheme for an aging population and applies them to the four key options resulting from combining the polar benefit and funding types; and (iii) outlines the need to complement the main old-age income scheme with other pillars and highlights key issues that all need further investigation.

\section{(i) Organizing consumption smoothing across a lengthening life span}

Faced with an aging population, the options for adjusting to the financial implications of rising expenditure and lagging revenues in a current service scenario are the same across earningsrelated pension schemes - whether funded or unfunded, defined benefit or defined contribution:

- Increase the contribution/saving rate

- Reduce the benefit level

- Require individuals to work longer/retire later from the labor market

In view of the uncertainty of future developments, and differentiated political resistance by age cohorts to policy options, but also quite likely due to a decision bias that favors taking a little bit of everything (the $1 / \mathrm{n}$ approach), policy makers typically prefer to take a "middle of the road" approach that is argued as fair or equitable. But is this the same approach an individual would select, assuming full information, full access to adequate consumption smoothing instruments across the life cycle, and neither the wish nor possibility to pass the burden on to the next generation?

The answer to this question requires the application of inter-temporal choice models, such as the life cycle approach, which stipulates that individuals make savings and labor supply decisions that smooth their consumption of goods and leisure across their entire individual lifetime. Before reporting the results of such models in a more realistic (and complex) setting, a simple numerical example is presented to make the point.

Assume an individual enters the labor force at age 15 and is expected to live until 75 with a retirement age of 60 (see Figure 7). With a constant wage of 100 , to achieve constant consumption across his/her life cycle, it would be optimal for him/her to save 25 percent of his/her wages per year. This would allow him/her a constant consumption level of 75 across the lifetime, with accumulated (actual or notional) wealth peaking at retirement. Now assume a change in the condition for the individual that is announced at the time he/she makes his/her inter-temporal choice: he/she starts to work at 20 instead of 15 (due to longer schooling) but is also expected to live for five more years, i.e., to 80 instead of 75 . If able to choose, would the individual keep his/her retirement age at 60 and pay a contribution rate of 33.3 percent, or would he/she prefer to retire at age 65 and keep his/her contribution and consumption rate 
unchanged? If everything else remains unchanged (such as health status, etc.), then choosing the second option is obviously preferred under normal preferences.

Figure 7: Consumption Smoothing Across the Life Cycle

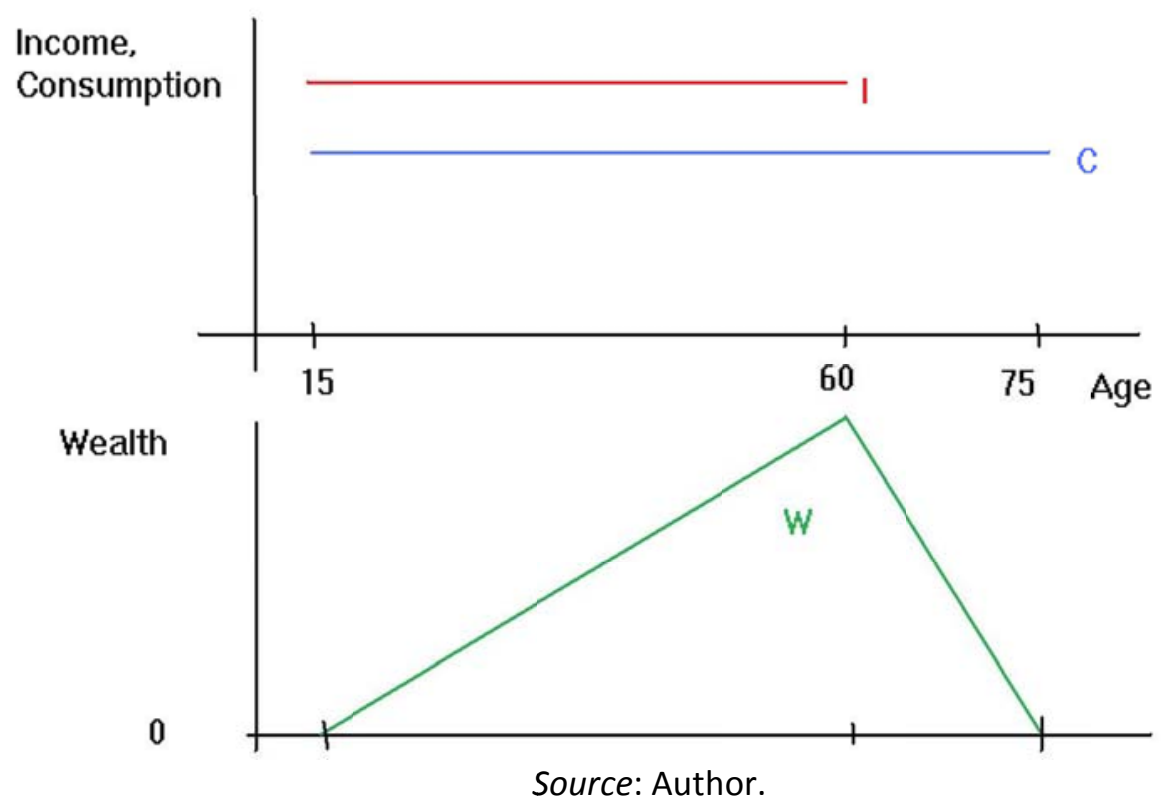

More realistic and/or complicated models of inter-temporal choice in light of population aging offer much richer but also more complex results that, to my knowledge, have not yet been summarized in a comprehensive survey article. And even if they have, the breadth of their approaches and assumptions would not allow for straightforward, simple conclusions and guidance for the selection of the "best" pension scheme. To get an appreciation of the complexity, the following key dimensions are highlighted:

- There is a diversity of approaches with an increasing number of results derived from (ex ante) simulations with non-computational or computational general equilibrium models building on overlapping generation models; the results from (ex post) econometric estimations try to distill historic country lessons that may or may not reflect the future demographic challenges or alternative policy approaches.

- The demographic data or assumptions in the model estimations typically reflect rising life expectancy (i.e., aging from above), but only a few cases reflect falling fertility rates (i.e., aging from below). This biases the results, as the effects are not symmetric.

- Perhaps most importantly, the computational general equilibrium models typically focus - for reasons of complexity reduction - on one or two variables to optimize the intertemporal utility function, such as consumption and leisure (retirement), labor supply and education, labor supply and health, etc. This gives important but only partial answers.

- Last but not least, different feedback loops from the selected variable path into economic performance lead to different conclusions and thus policy prescriptions and, 
perhaps, pension scheme selection. E.g., the effect of a lower number of children may give rise to higher education investments that affect productivity and economic outcomes that are potentially able to at least partially compensate for population aging effects (see, for example, Börsch-Supan 2008, and Lee and Mason 2010a).

From the impressive scope of theoretical, simulation, and empirical papers, the following key conclusions are derived. They may not be completely representative, but they do have a bearing on the pension system selection:

- If individuals have to bear the full burden of aging from above (i.e., because of an actuarial structure, they cannot pass the burden on to others), the "natural" adjustment reaction for both funded and unfunded schemes is essentially to expand labor market participation/delay retirement, with limited appetite for more pre-saving/higher contributions or reduced benefit levels.

- In the case of aging from below, the implicit rate of return for unfunded schemes definitely and the explicit rate of return of funded schemes quite likely are subject to reduction. This change in the remuneration of contributions changes the price of leisure/labor, which has an income and substitution effect with an undetermined net result on labor supply, savings, and retirement decisions. Yet this is unlikely to avert the dominance of an extended activity span as a key reaction to an increase in life expectancy.

- Regarding the willingness to accept/choose lower benefits as an adjustment reaction to population aging, the empirical evidence signals situation-specific results. For example, cutting a too generous (unfunded) benefit simply reduces transfers inter vivo or at death, but has a limited labor supply reaction; similarly, a cut in old-age benefits is typically preferred to the risk of unemployment at old-age.

\section{(ii) Criteria for and choice of pension schemes in an aging population}

Against the background of the prior analyses and the conjectured dominance of a labor supply strategy to address the sustained life expectancy increase, what are the criteria that matter most for a (general and mandated) pension scheme to adjust most easily to an aging population? The following five criteria are suggested to be in the forefront:

1. Incentives to stay in the labor market; no bias for retirement at the earliest possible date; incentives to remain formal and skilled, healthy and motivated, etc.

2. The capability to adjust automatically to a change (increase) in a cohort's life expectancy.

3. An adjustment mechanism (preferably automatic) to demographic and economic shocks to keep the system financially afloat.

4. A structure that offers high intra- and inter-generational equity; i.e., a low rate of variation in the rate of return within and across age cohorts.

5. Easy and least distortive integration of redistributive objectives into scheme design/coordination with other redistributive programs. 
The first two criteria require a scheme that supports life cycle planning in an unbiased manner (i.e., an actuarial/defined contribution-type structure). Criterion 3 is a macro condition to keep pension liabilities and assets in sync. Criterion 4 calls for an aggregate funding approach to smooth rate of return variations across individuals and cohorts, while criterion 5 is a design and implementation requirement.

Which pension schemes are able to fulfill these criteria or can be excluded for the lack of ability thereof? To facilitate the analysis and selection, it is useful to distinguish between the two key dimensions of pension schemes: the benefit type (defined benefits versus defined contribution) and the funding type (unfunded versus funded). Very simply put, in typical defined benefits schemes, the benefit is determined by the salary level at career-end and the number of years worked. In a defined contribution scheme, the benefit is determined by the accumulated contributions paid throughout the whole career, the interest earned, and the remaining life expectancy at retirement. In unfunded schemes, the contributions in each period are used to pay the benefits of this very period, creating an implicit inter-generational contract. In a funded scheme, financial assets are set aside to cover the liabilities created by the contributions paid in. Table 2 provides an overview of the combination of these dimensions, their basic characteristics, and examples of countries that have implemented the different schemes. NDC is thereby the new kid on the block (and Box 1 offers a quick introduction).

Table 2: Pension Schemes' Variation: Combining Benefit and Funding Options

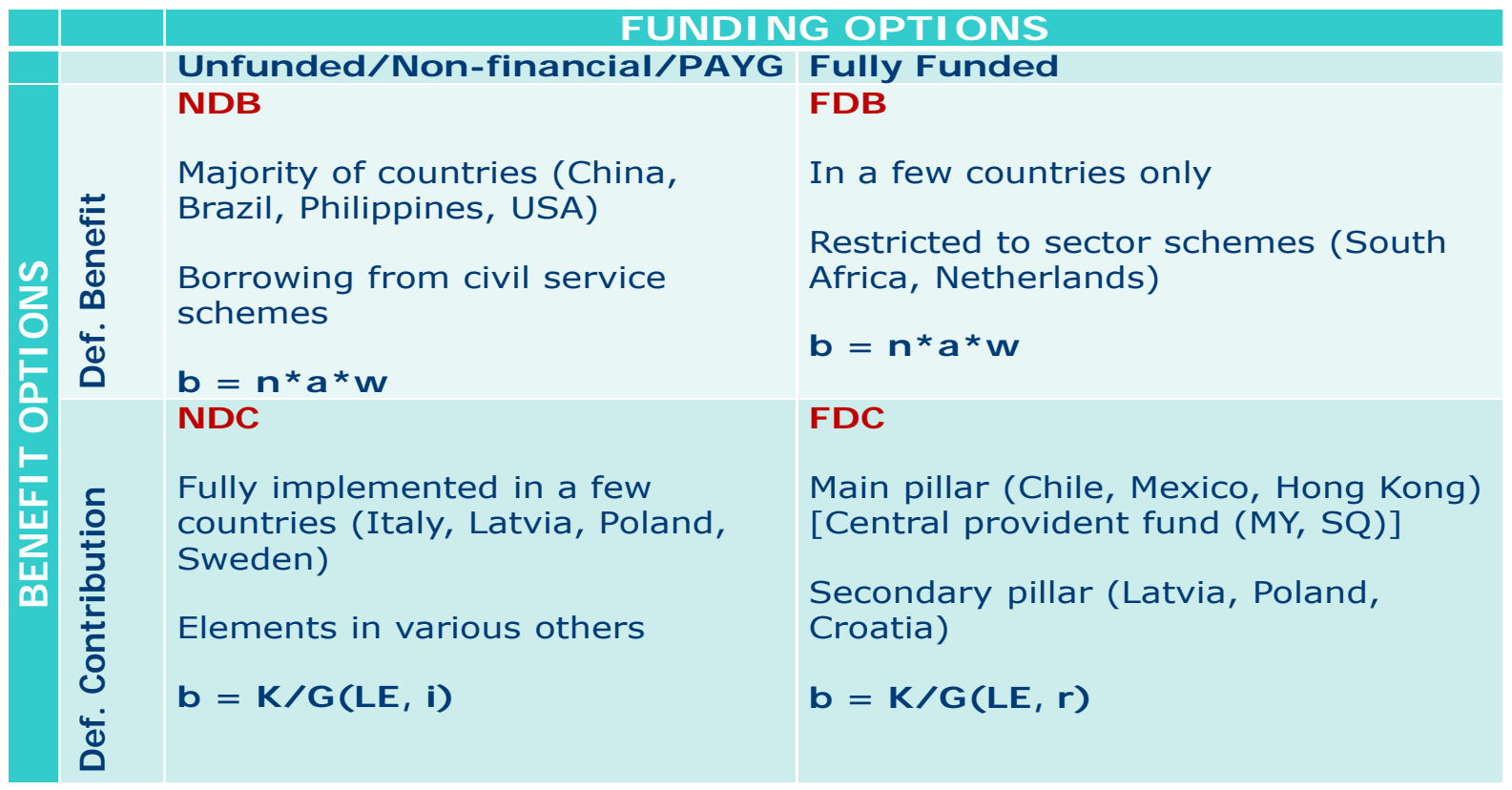

Notes: b: benefit; $\mathrm{n}$ : years of contribution; a: annual accrual factor; $\mathrm{w}$ : wage/pension base; $\mathrm{K}$ : Accumulated capital at retirement; G: function of life expectancy at retirement (LE) and non-financial interest rate (i), or financial interest rate $(r)$. Source: Author. 


\section{Box 1: The Non-Financial Defined Contribution (NDC) Scheme}

Non-financial (also called notional) defined contribution (NDC) schemes mimic a centralized FDC scheme but remain essentially unfunded. The operation of a NDC scheme is very simple and transparent: contributions (by the individual and/or his employer) are recorded in an individual account on which a notional interest rate is paid. At retirement, the non-financial capital is transformed into an annuity based on the prospective cohort life expectancy and taking account of the expected future notional interest rate. This means that the system pays out what an individual paid in but not more, and what he/she paid in, he/she gets out. This approach satisfies criteria 1 and 2 . To achieve financial sustainability, the notional interest rate is proxied by a measure consistent with the internal rate of an unfunded scheme such as the growth of the contribution base, and benefits are indexed accordingly. To satisfy criterion 3 fully, the NDC scheme needs to have an additional balancing mechanism that further corrects the notional interest rate and/or the annual benefit indexation if the liabilities deviate from the (contribution) assets. The central rate calculation and the smoothing approach with a reserve fund help satisfy criterion 4 . Integrating a distributive consideration, such as a period of unemployment or child raising, can be easily compensated for by making adequate transfers to the individual's account, thus satisfying criterion 5. Yet unlike in an NDB scheme, the transfer has to be in hard cash, not future promises of payment.

This pension reform revolution started in the mid-1990s in Italy, Latvia, Poland, and Sweden, all of which implemented NDC schemes almost by the book and inspired other countries to copy or mimic their main features (e.g., Norway implemented its scheme in 2011; Egypt legislated one in 2010 but is awaiting its implementation). This also inspired reform visions for other countries, such as China (see Dorfman et al. 2013). The NDC schemes in Italy, Latvia, Poland, and Sweden weathered the recent global crisis relatively well, but their experience gives rise to suggestions for improvements to even better confront and support the aging of populations (see Holzmann, Palmer and Robalino 2012 and 2013).

To guide the selection, it is important to assess the extent to which the main schemes comply with the criteria set out above (summarized in Table 3):

- Defined benefit schemes, whether unfunded (NDB) or funded (FDB), are typically not in the solution set. Traditional DB schemes typically violate all five criteria, except, at times, the distributive objectives. Making them comply with the criteria through parametric reforms is cumbersome or if successful makes them germane to a defined contribution scheme only in a more complicated manner.

- Defined contribution schemes, whether unfunded (NDC) or funded (FDC), are generally more promising. Differences emerge to the extent that the rate of return of funded schemes ( $r$ ) exceeds the rate of return in unfunded schemes $(g)$, and in the case of centralized versus decentralized implementation (only relevant for funding and there both in the accumulation and disbursement phase). 
- If $r \geq g$, then in principle FDCs dominate NDCs with regard to labor market incentives; as the latter keep a tax element, this may play also in favor of FDCs with respect to inter- and intra-cohort equity considerations under centralized funding. Yet the latter has a bad track record with respect to the realized rate of return, albeit more recent experience is somewhat more promising (see Rajkumar and Dorfman, 2011).

- As regards decentralized funding, FDCs do not deliver well on inter- and intra-cohort equity as main differences in the rate of return for individuals are bound to emerge. And such differences continue through the way the life annuity is provided in NDC and FDC schemes (see Table 4).

- While $r \geq g$ is necessary for dynamic efficiency of an economy, this does not occur systematically in real-world pension schemes. Particularly in emerging economies, recorded rate of wage growth typically exceeds the realized rate of return of pension funds for decades.

- Furthermore, what should matter from a welfare perspective is the comparison of the risk adjusted rate of return and the volatility of $g$ is typically well below that of $r$. But how best to adjust the returns for risk is far from clear conceptually (Hinz et al. 2010).

- For a comparison and selection guidance, it is the future development of $r$ versus $g$ under an aging population that matters, rather than the past. While aging will probably have a negative impact on $g$, there are also good reasons for why $r$ may be negatively affected; e.g., due to a deteriorating saver/dis-saver ratio or to indirect impacts from lower economic growth (this latter channel is little explored; see Holzmann 2009).

- Last but not least, the near future is also likely to be influenced by the fallout of the financial crisis and governments' strategies for balancing their accounts and reducing their high public debt. Both cast a high degree of uncertainty on the level of future returns in funded and unfunded schemes. 
Table 3: Applying the Criteria

\begin{tabular}{|c|c|c|c|}
\hline Criteria & DB & DC & $\begin{array}{l}\text { Unfunded vs } \\
\text { Funded DC schemes }\end{array}$ \\
\hline $\begin{array}{l}\text { i. Labor market } \\
\text { incentives }\end{array}$ & & $\mathrm{Y}$ & $\begin{array}{c}\text { Depends on } r \geq \mathrm{g} \text {, with possible } \\
\text { advantages for funding }\end{array}$ \\
\hline $\begin{array}{l}\text { ii. Adjustment to life } \\
\text { expectancy }\end{array}$ & & Y & broadly neutral \\
\hline $\begin{array}{l}\text { iii. Ease od adjustment } \\
\text { to shocks: } \\
\text { Economic, financial \& } \\
\text { demographic }\end{array}$ & & Y & $\begin{array}{l}\text { Depends on type and size of } \\
\text { shock and can go both ways }\end{array}$ \\
\hline $\begin{array}{l}\text { iv. Intra- and inter- } \\
\text { personal equity (similar } \\
\text { rate of return) }\end{array}$ & & Y? & $\begin{array}{c}\text { Depends on } r \geq g \\
\text { and } \\
\text { centralized vs decentralized } \\
\text { approaches }\end{array}$ \\
\hline $\begin{array}{l}\text { v. Integration of } \\
\text { redistribution objectives }\end{array}$ & Y? & $Y$ & broadly neutral \\
\hline
\end{tabular}

Source: Author.

Table 4: FDC and NDC Arrangements and Equity Criteria

\begin{tabular}{|l|l|l|}
\hline $\begin{array}{l}\text { Unfunded } \\
\text { (NDC) }\end{array}$ & Accumulation & Disbursement \\
\hline Funded (FDC) & $\begin{array}{l}\text { RoR: uniform } \\
\text { (central provident } \\
\text { fund) }\end{array}$ & $\begin{array}{l}\text { Annuity: typically none, } \\
\text { but may self operate } \\
\text { (uniform) or outsource to } \\
\text { private sector (hetero) }\end{array}$ \\
\hline $\begin{array}{l}\text { RoR: heterogeneous } \\
\text { (private pension funds) }\end{array}$ & $\begin{array}{l}\text { May have annuity from } \\
\text { private sector (hetero) or } \\
\text { social security (uniform) }\end{array}$ \\
\hline
\end{tabular}

Source: Author.

Summing up this preliminary analysis for guidance on the main pension scheme selection for an aging population, the following key conclusions are proposed:

- There are convincing conceptual considerations and empirical evidence that defined contribution plans dominate defined benefit plans in their capacity to address population aging well.

- Within the class of defined contribution plans, the selection between funded and unfunded schemes is much less straightforward with and without population aging, and the latter does not make the selection easier.

- There are too many conceptual, empirical, and operational questions left open to offer an easy answer and there should be a call for more research. However, the actual 
selection may ultimately be dictated by the existing scheme and the difficult political and economic transition issues any change would imply.

\section{(iii) Complementing the main pension pillar(s)}

To address population aging well, one has to be mindful that NDC (as first pillar) or FDC (as second pillar) schemes are only part and parcel of a broader pension system that includes other pillars as well as social benefit programs covering a diverse set of objectives. In particular, these include (see Holzmann and Hinz 2005):

- A zero pillar that addresses old-age poverty issues through top-ups or guaranteed income provisions for those who have insufficient income under their contributionbased main pillar or who never have an opportunity to acquire pension rights.

- A voluntary third pillar that addresses the coverage gap for informal sector workers via special or universal provisions.

- A voluntary third pillar that offers supplementary savings opportunities for those covered under the general scheme but in need of supplementary benefit coverage.

- A residual fourth pillar that offers income and service support to the elderly through family assistance, public health care, or other informal or formal assistance (such as the provision of meals and transport).

- Other social insurance programs that have a close link with old-age insurance, in particular for disability and survivorship.

The design and implementation of these programs are geared toward their own objectives but need to be adjusted to deliver well under the profound demographic shifts. In addition, these programs need to be reviewed and adjusted so as not to contradict the objectives and envisaged functioning of the main pillar(s) and thus their capacity to address population aging. The list of potential considerations is very long, thus only a few key elements are presented here for further discussion:

- How to design a zero pillar to address old-age poverty? Choices include: through exante or ex-post transfers; universal or means-tested benefits; categorical (social pension) or general (social assistance) provisions. Each of these options creates different incentives for labor supply and retirement decisions.

- What is the impact on informality? Do generous zero pillar provisions increase the tax wedge for formal sector workers and thus create a destructive spiral toward informality that may lead to death of the mandated earnings-related scheme? Such considerations seem to be highly relevant for MICs with a high and sustained level of informality (see Levy 2008).

- What is the impact of retirement decisions on the main pension pillar? Even in the best of worlds, the existence of a zero pillar will affect labor supply and retirement decisions. For the poor, the eligibility for guaranteed income from a certain age onward creates a kink in the inter-temporal budget constraint and thus incentives to retire at the eligibility age. This calls for eligibility ages consistent with the main pillar and their indexation with rising life expectancy. 
- How should informal workers be covered? Most LICs and MICs have difficulties covering informal sector workers under the general pillar. Offering voluntary schemes and matching contributions is increasingly seen as a promising approach to increase coverage. But are these effective? Should this happen under a general or a special third pillar? And what is the exit strategy?

- How can formal workers be enticed into additional retirement saving? As public generosity under the main pillar decreases, governments are looking for strategies to entice individuals to make up the difference through voluntary savings. To this end, they offer indirect fiscal incentives (tax preference) and/or subsidies (matching contributions) from employers and/or the government. Again, are these measures effective in terms of participation, saving effects, and fiscal outcomes?

- How should disability and survivors' programs be reformed? Both traditional programs need a review and restructuring if and as the main scheme moves from DB to DC. In addition, there are many good general arguments for reform that get accentuated under aging. For example, increasing the retirement age may not be effective if an "escape road" via disability benefits exists. And the objective of high female labor force participation is likely to be undermined by the dis-incentives of traditional survivors' pensions.

While the stocktaking of international experience on coverage expansion and poverty alleviation has increased our knowledge of design options and policy effectiveness (see Holzmann, Robalino and Takayama 2009; and Hinz, Holzmann, Tuesta and Takayama 2013), it has also made us aware of the main knowledge gaps that still exist around approaches to marry design incentives for later retirement with income guarantees for the poor under population aging.

\section{Conclusions}

Population aging as the result of continued increases in life expectancy (and reduced fertility rates) is a phenomenon relatively new to mankind. It is hardly a handful of generations old in advanced economies and is spreading to all countries across the globe. This revolution requires a review and revision of all societal institutions, from marriage to retirement income schemes. Mere parametric changes and tinkering at the margin of existing retirement income programs will be neither sufficient nor helpful.

To start a reform revolution, it will be very useful to revise and adjust the conventional measurement of aging, in particular the definition of the onset of being considered "elderly" or "old." The retrospective measurement of aging loses its meaning with continued rising life expectancy due to a reduction in mortality rates at all ages, a reduction in morbidity, and a postponement of disability into higher ages. Using a prospective measurement of age makes the point that the new " 70, " is the old " 60 " half a century ago, with further projected increases in the decades to come (Vaupel 2010).

Such a new perspective on aging and a related dynamic adjustment in the old-age dependency ratio from ages $60+/(20-59)$ to $70+/(20-69)$ promises to address the distributive question of population aging: how to split the economic pie. This still leaves concerns about the 
growth of the pie in an aging population and the fate of productivity under an older workforce. There are empirical indications that this can be addressed, but this will not happen automatically - it requires policies for which design and implementation may not yet be at hand.

Against this background, old-age financial protection programs need to be selected in support of such policies that keep individuals healthy, skilled, and motivated to stay in the labor market and be productive. This is claimed to be less of a problem, as main progress in our understanding has been made to this end, with a well-run FDC scheme (in a decentralized and market-based version, as in Chile, or a central version with provident fund plus annuity provision at retirement) and a non-financial defined contribution scheme (as in Sweden and Poland) emerging as strong candidates.

The main concerns for addressing aging well for individuals and society are centered around the necessary adjustments of the labor market and education institutions, and marrying the retirement postponing effects of an actuarial pension structure under the main pillar(s) with the poverty-addressing objectives of the zero pillar. Addressing both issues well is impeded by major knowledge gaps, even in advanced economies. And both issues are compounded in LICs and MICs, typically characterized by large, and t times growing, informal economies. This may call for radical new solutions, such as (funded or notional) account systems for all, with basic and matching contributions by the government for the needy (see Holzmann 2013).

Establishing baseline scenarios for unchanged policies in the face of population aging is critical to gain an appreciation of the task at hand. The proposed next step is to tease out the changes required in labor force participation, retirement age, health status, and productivity profiles to address the challenges of population aging in economic, fiscal, and social terms. This solution vector will then be the starting position in the search for new policies. The identification of an appropriate old-age financial protection system is critical to this end, but is not the only ingredient. 


\section{References}

Antonovsky, Aaron. 1967. "Social Class, Life Expectancy and Overall Mortality." The Milbank Memorial Fund Quarterly 45 (2, Part 1): 31-73.

Aterido, Reyes, Mary Hallward-Driemeier, and Carmen Pagés. 2011. “Does Expanding Health Insurance Beyond Formal-Sector Workers Encourage Informality? Measuring the Impact of Mexico's Seguro Popular." IZA Discussion Paper No. 5996. Bonn: IZA.

Bauer, Nikolaus, and Helmut Mauermann. 2010. "How BMW is Defusing the Demographic Time Bomb." Harvard Business Review March.

Bloom, David E., and Alfonso Sousa-Poza. 2013. "Ageing and productivity." FZID Discussion Papers, No. 63-2012, http://nbn-resolving.de/urn:nbn:de:bsz:100-opus-8075, opening paper in Labour Economics 2013 (22) supplement: Ageing and Productivity.

Börsch-Supan, Axel. 2008. "The Impact of Global Aging on Labor, Product, and Capital Markets." Population and Development Review 34: 52-77.

Bowling, Ann, and Paul Dieppe. 2005. "What is successful ageing and who should define it?" British Medical Journal 331 (7531): 1548-1551.

Burger, Oskar, Annette Baudisch and James Vaupel. 2012. "Human mortality improvement in evolutionary context". PNAS, October 15.

Chand, Sheetal, and Albert Jaeger. 2000. "Aging Populations and Public Pension Schemes." IMF Occasional Paper 147. Washington, DC: International Monetary Fund.

Chawla Mukesh, Gordon Betcherman, and Arup Banerji. 2007. FROM RED TO GREY: The "Third Transition" of Aging Populations in Eastern Europe and the Former Soviet Union. Washington, DC: World Bank.

Cotlear, Daniel. 2011 "Population Aging - Is Latin America Ready?" Directions in Development, Human Development. Washington, DC: World Bank.

Dorfman, Mark, Robert Holzmann, Philip O’Keefe, Dewen Wang, Yvonne Sin, and Richard Hinz. 2013. China's Pension System - A Vision. Washington, DC: World Bank.

Eggleston, Karen, and Victor Fuchs. 2012. "The New Demographic Transition: Most Gains in Life Expectancy Now Realized Late in Life." Journal of Economic Perspectives 26 (3): 137-156.

Erdman, Palmore. 1979. "Predictors of Successful Aging." The Gerontologist 19 (5 Part 1): 427431.

Finkel, D., C.A. Reynolds, J.J. McArdleJ, and N.L. Pedersen. 2007. "Cohort differences in trajectories of cognitive aging." Journals of Gerontology Series B-Psychological Sciences and Social Sciences 62(5):286-294. 
Feyrer, J. (2007). "Demographics and Productivity". Review of Economics and Statistics 89: 100109.

Fisher, Bradley J. 1995. "Successful Aging, Life Satisfaction, and Generativity in Later Life." The International Journal of Aging and Human Development 41 (3): 239-250.

Franklin, Nina C., and Charlotte A. Tate. 2009. "Lifestyle and Successful Aging: An Overview." American Journal of Lifestyle Medicine 3 (1): 6-11.

Hinz, Richard, Heinz P. Rudolph, Pablo Antolin, and Juan Yermo. 2010. Evaluating the Financial Performance of Funds. Washington, DC: World Bank.

Hinz, Richard, Robert Holzmann, David Tuesta, and Noriyuki Takayama, eds. 2013. Matching Defined Contribution (MDC) Schemes: A Promising Pension Design to Enhance Coverage and Benefit Level? Washington, DC: World Bank.

Holzmann, Robert. 1988. Reforming Public Pensions. Paris: Organisation for Economic Cooperation and Development.

Holzmann, Robert. 2009, ed. Aging Populations, Pension Funds, and Financial Markets: Regional Perspectives and Global Challenges for Central, Eastern, and Southern Europe.

Washington, DC.: World Bank-ERSTE Foundation.

Holzmann, R., Richard Hinz, and World Bank Team. 2005. Old-Age Income Support in the Twenty-first Century: An International Perspective on Pension Systems and Reform. Washington, DC: World Bank (also available in Arabic, Chinese, Russian and Spanish).

Holzmann, Robert, David A. Robalino, and Noriyuki Takayama, eds. 2009. Closing the Coverage Gap - The Role of Social Pensions and Other Retirement Income Transfers. Washington, DC: World Bank.

Holzmann, Robert, Landis Mackellar, and Jana Repansek. 2009, eds. Pension Reform in SouthEastern Europe: Linking Pension Reform with Labor and Financial Market Reforms. Washington, DC.: World Bank.

Holzmann, Robert. 2009, ed. Aging Populations, Pension Funds, and Financial Markets: Regional Perspectives and Global Challenges for Central, Eastern, and Southern Europe.

Washington, DC.: World Bank-ERSTE Foundation.

Holzmann, Robert, Edward Palmer, and David Robalino, eds. 2012. NDC Pension Schemes in a Changing Pension World, Volume 1: Progress, Issues, and Implementation. Washington, DC: World Bank and Swedish Social Insurance Agency.

2013. NDC Pension Schemes in a Changing Pension World, Volume 2: Gender, Politics, and Financial Stability. Washington, DC: World Bank and Swedish Social Insurance Agency. 
Holzmann, Robert. 2013. "Global pension systems and their reform: Worldwide drivers, trends and challenges”, International Social Security Review 66 (2, April-June): 1-29.

International Institute for Applied System Analyses (IIASA): "International Variation in Productivity Potential - Secondary Education." Laxenburg: IIASA, mimeo.

Ilmakunnas, Pekka, Jan van Ours, Vegard Skirbekk, and Matthias Weiss. 2007. "Ageing and Producivity." Ninth European Conference of the Fondazione Rodolfo DeBenedetti "Health, Longevity and Productivity," held in Limone sul Garda, Italy, May, Vol 34.

IImarinen, Juhani. 2005. Toward a Longer Working Life. Ageing and The Quality of Worklife in the European Union. Helsiniki: Finish Institute of Occupational Health.

IMF (International Monetary Fund). 2004. World Economic Outlook: The Global Demographic Transition, Chapter 3: How will Demographic Change Affect the Global Economy? Washington, DC: International Monetary Fund, September.

2012. World Economic Outlook, Chapter 4: The Financial Impact of Longevity Risk. Washington, DC: International Monetary Fund, April.

Juvin, Herve. 2005. L'avènement du corps. Paris: Gallimard.

Lee, Ronald, and Andrew Mason. 2010a. "Some macroeconomic aspects of global population aging." Demography 47(1, Supplement): S151-S172.

2010b. "Fertility, human capital, and economic growth over the demographic transition", European Journal of Population 26(2), 159-82.

Lee, Sang-Hyop, Andrew Mason and Donghyun Prk. 2013. "Overview: why does population aging matter so much in Asia? Population aging, economic growth, and economic security in Asia. In Park et al. eds. Op cit. 1-31.

Levy, Santiago. 2008. Good Intentions, Bad Outcomes. Washington, DC: Brookings Institution.

Lopez Ulloa, Beatrice Fabiola, Valerie Moller, and Alfonso Sousa-Poza. 2013. "How does Subjective Well-Being Evolve with Age? A Literature Review." IZA Discussion Papers No. 7328, April. Forthcoming in Journal of Population Aging.

Marin, Bernd, and Zaidi Ashgar. 2007. Mainstreaming Aging: Indicators to Monitor Sustainable Policies. Vienna: Ashgate/European Center Vienna.

OECD (Organisation for Economic Co-operation and Development). 1998. Maintaining Prosperity in an Ageing Society. Paris: OECD. 
.2005. "Ageing Populations: High Time for Action." Background paper prepared by the OECD Secretariat. Meeting of G8 Employment and Labour Ministers, London, 10-11 March 2005. Paris: OECD.

2006. Live Longer, Work Longer: Ageing and Employment Policies. Paris: OECD.

2012. Pensions at a Glance: Asia/Pacific 2012. Paris: OECD.

Oeppen, J., and J.W. Vaupel. 2002. "Demography - Broken Limits to Life Expectancy." Science 296: 1029-1031.

Park, Donghyun, Sang-Hyop Lee and Andrew Mason, eds. 2012. Aging, Economic Growth, and Old-Age Security in Asia. Cheltenham, UK \& Northampton, MA.: Edward Elgar Publishing and Asian Development Bank.

Phang, Hanam S., ed. 2011. Population Ageing and Productivity in Asian Countries. Report of the APO Research on Aging Society. Tokyio: Asian Productivity Organization.

Prettner, K., D.E. Bloom, , and H. Strulik. , 2013. "Declining fertility and economic well-being: do education and health ride to the rescue?" Labour Economics Vol. 22 supplement: Ageing and Productivity.

Pruchno, Rachel A., Maureen Wilson-Genderson, and Francine Cartwright. 2010. "A Two-Factor Model of Successful Aging." Journal of Gerontology - Series B, Psychological Sciences and Social Sciences 65B (6): 671-679.

Rajkumar, Sudhir and Mark Dorfman, eds. Governance and Investment of Public Pension Assets. Washington, DC: World Bank, 2011

Ribe, Helena, David Robalino, and Ian Walker. 2012. From Right to Reality: Incentives, Labor Markets, and the Challenge of Achieving Universal Social Protection in Latin America and the Caribbean. Latin American Development Forum Series. Washington, DC: World Bank.

Rowland, Donald T. 2009. "Global Population Aging: History and Prospects." In International Handbooks of Population, ed. Peter Uhlenberg. Volume 1: 37-65.

Sanderson, Warren, and Sergei Scherbov. 2007. "A New Perspective on Population Aging." Demographic Research 16, Article 2: 27-58, January 16.

Skirbekk, Vegard. 2008. "Age and productivity potential: a new approach based on ability levels and industry-wide task demand." Population and Development Review 34: 191-207.

Skirbekk, Vegard, Elke Loichinger and Daniela Weber. 2012. "Variation in cognitive functioning as a refined approach to comparing aging across countries." PNAS 109 (3): 770-774.

Skirbekk, Vegard, Marcin Stonawski, Eric Bonsang and Ursula M. Staudinger. 2013. "The Flynn effect and population aging." Intelligence 41: 169-177. 
Thang, Leng Leng. 2011. "Population aging, older workers and productivity issues: the case of Singapore." Journal of Comparative Social Welfare 27 (1): 17-33.

United Nations. 2002. World Population Prospects: The 2000 Revision. New York: UN. .2011. World Population Prospects: The 2010 Revision. New York: UN.

U.S. Dept. of Labor 2007. "Skills and Age." Washington, DC: Department of Labor, mimeo.

Van Ours, Jan. 2010. “Age, wage, and productivity." VOX, March 5, 2010. http://www.voxeu.org/article/ageing-populations-and-productivity, accessed March 12, 2013.

Van Ours, Jan, and Lenny Stoeldraijer. 2010. "Age, wage and productivity." Discussion Paper 2010-12, CentER, Tilburg University.

Vaupel, James, W. 2010. "Biodemography of human ageing." Nature 464(7288): 536-542. http://dx.doi.org/10.1038/nature08984.

Vienna Institute of Demography. 2013. European Demographic Data Sheet 2012. Vienna: Austrian Academy of Science. http://www.oeaw.ac.at/vid/datasheet/index.html

Walker, Alain. 2006. "Active ageing in employment: Its meaning and potential." Asia-Pacific Review 13 (1): 78-93. 